\title{
CONSUMERS BELIEVE THAT PRODUCTS WORK BETTER FOR OTHERS
}

\author{
Evan Polman \\ University of Wisconsin-Madison \\ Ignazio Ziano \\ Grenoble Ecole de Management \\ Kaiyang $\mathrm{Wu}$ \\ University of Wisconsin-Madison \\ Anneleen Van Kerckhove \\ Ghent University
}

\begin{abstract}
Consumers tend to see themselves in a positive light, yet we present evidence that they are pessimistic about whether they will receive a product's benefits. In 15 studies $(N=6,547$; including nine pre-registered), we found that consumers believe that product efficacy is higher for others than it is for themselves. For example, consumers believe that consuming an adult coloring book (to inspire creativity), a sports drink (to satisfy thirst), medicine (to relieve pain), or an online class (to learn something new) will have a greater effect on others than on themselves. We show that this bias holds across many kinds of products and judgment-targets, and inversely correlates with factors such as product familiarity, product usefulness, and relationship closeness with judgment-targets. Moreover, we find this bias stems from consumers' beliefs they are more unique and less malleable than others, and that it alters the choices people make for others. We conclude by discussing implications for research on giftgiving, advice-giving, usership, and interpersonal social, health, and financial choices.

Keywords: perceived product efficacy; self-other differences; stimulus sampling; linear mixed effects modeling; perceived uniqueness; perceived malleability
\end{abstract}


Why do people buy products? Research in consumer behavior has identified situational and dispositional factors that influence whether consumers will buy a product, such as persuasive appeals, including sights, sounds, and smells; competitors' offerings and prices; and buyers' values, goals, needs, emotions, finances, social network, and identity. Despite its breadth, nearly all of this research assumes one of the more practical reasons people buy products: for the benefits they expect to receive from consuming them. While products can serve multiple benefits and purposes, consumers' expectation that a product will deliver on its promised purpose is known as its perceived product efficacy. When consumers believe products are more efficacious, they are more likely to purchase them (Folkes, Martin, and Gupta 1993). In this paper, we examine whether consumers believe products will be as efficacious for themselves as for other consumers, a factor that is likely to influence their interpersonal decisions, such as what product (and how much of it) they choose for others.

\section{SELF-OTHER DIFFERENCES IN PERCEIVED PRODUCT EFFICACY}

Products, including material possessions, are viewed as part of the extended self(Belk 1988). As such, they contribute to self-concept, self-identity, and self-expansion (Beggan 1992; Polman and Maglio 2017; Wicklund and Gollwitzer 1982). Given that consumers tend to make judgments in a self-enhancing manner (Dunning 2007), one might expect consumers to believe that products will work better for themselves than for others. After all, products deliver results desired by consumers. To date, however, the research literature is thin when it comes to people's judgments of how well products will work for themselves compared to others. Related research on product judgments has found that, as compared to themselves, consumers believe others are willing to pay more for products (Frederick 2012; Kurt and Inman 2013), seek more product variety (Ratner and Kahn 2002), buy fewer products with 
their money (Polman, Effron, and Thomas 2018), and consider performance-enhancing products as a natural enabler of their own abilities but an unfair embellishment of other people's (Williams and Steffel 2014).

What has not been studied in the literature are people's perceptions of how well products work for themselves compared to others. This question is of theoretical importance because one of the primary goals of research in psychology is uncovering how people make sense of others' responses to causal effects (Hastie and Pennington 2000; Malle 1999). For instance, in order to interact with others, people need to intuit others' minds, and predict how others react to the stimuli in their environment (Waytz, Schroeder, and Epley 2014). In a consumer context, there is perhaps no stimulus more relevant or ubiquitous than a product stimulus. In the United States, products are so prevalent that Americans own, on average, 300,000 of them (MacVean 2014) - generating myriad opportunities in which judgments of others accompany judgments of products. Thus, our research can enrich scholarship on social judgment by examining the environmental stimuli that envelope people's everyday lives: products. Moreover, because we study product efficacy judgments, our research adds to a fundamental area in consumer behavior. It stands to reason that product purchases are based on prospective consumers' beliefs of product efficacy, yet the lion's share of research on consumer behavior focuses on the effects of internal dispositions and/or external situations. The literature overlooks a more obvious and common reason for why people buy products: the benefit that people expect to receive from consuming them.

For practical reasons too, it is valuable to link self-other differences with product efficacy judgments, because these judgments are likely to guide people's behavior toward others. As social animals, consumers not only look out for themselves, but take care of others - for example, by buying caregiving products for others (Garcia-Rada, Steffel, Williams, and Norton 2021). Indeed, people help others in various ways by giving them 
money, advice, favors, gifts, or medicine to improve others' well-being. These offerings vary in how much they help others. In terms of goods and services, not all consumer products are equally efficacious (just like not all advice is equally effective), meaning that how much of a product people choose for others may be just as important as what product people choose for others. Such, then, by believing that others benefit more or less from products' efficacy, people may choose different amounts of products for them-which can directly influence others' well-being or health.

\section{Research on Perceived Product Efficacy}

As research has shown, details of a product's supposed efficacy are often on display, illustrated and described on packaging and in advertisements (Zhu, Billeter, and Inman 2012). Studies have found that highlighting a product's benefits changes consumers' beliefs about its efficacy and whether they choose to buy it (Chae, Li, and Zhu 2013; Dawar and Parker 1994; Kupor and Laurin 2020). In fact, consumers' product efficacy beliefs have been found to increase actual product efficacy through a placebo effect (Brasel and Gips 2011; Irmak, Block and Fitzsimons 2005; Van Bergen, Irmak, and Sevilla 2020). Moreover, perceived product efficacy alters consumption volume: consumers use more of a product when they believe it is less effective (Lin and Chang 2012; Zhu et al. 2012).

Research has not only identified the effects of product efficacy beliefs, but also what changes these beliefs. For example, single-serve packages signal to consumers that the products they contain will fulfil their purpose (Ilyuk and Block 2016). In advertisements, the spatial closeness between a product and its purported benefit increases product efficacy perceptions among consumers (Chae et al. 2013). For instance, consumers believe that an anti-cockroach spray is more effective when it is pictured very close to a dead cockroach 
rather than far from one. Likewise, advertisements that include visuals of intermediate steps toward an intended benefit, such as showing gradual gains from a hair-loss treatment rather than simply before-and-after results, will more persuasively communicate perceived product efficacy (Cian, Krishna, and Longoni 2020). Similarly, presenting multiple replicates of a product and highlighting how many people produced it lead consumers to perceive products as more efficacious (Maglio et al. 2020; Van Bergen et al. 2020).

\section{Social Factors}

Although existing research has identified antecedents of perceived product efficacy, this stream of literature has not examined social factors. Critically, social factors permeate consumer behavior, from shopping in the presence of others, making joint purchasing decisions, choosing gifts, to making choices that are judged or influenced by others (Argo and Dahl 2020; Gorlin and Dhar 2012; Liu, Dallas and Fitzsimons 2019). Indeed, consumers often purchase products for others (Wu, Moore, and Fitzsimons 2019) and with others (Brick et al. 2021; Garcia-Rada, Anik, and Ariely 2019), decisions that are plausibly affected by how much consumers believe products will affect others. Thus, we examine not only the judgments that consumers make of products' effects for themselves but for others too.

Past findings would suggest that consumers believe they receive more utility from products than others because they see themselves in a more positive light-for example, as more likely to receive good things in life (Klein 1997; Weinstein 1980). In complement, theories of motivated reasoning, self-serving attributions, and positive illusions (Alicke, 1985; Kunda, 1990) would suggest that people view products as benefitting themselves more than others. While these theories could bear on people's judgments of how their product usage compares to others' product usage, we predict that when it comes to predicting a product's 
efficacy, two distinct self-serving biases will perversely work in parallel to produce a nonself-serving bias in perceived product efficacy. The first bias, perceived uniqueness, describes consumers' belief they are more unique than others, which should lead them to believe they require more custom, fine-grained products than others in order to receive potential benefits. This should increase the likelihood that consumers will believe products work better for others. The second bias, perceived malleability, describes consumers' common belief they are more consistent than others - more rooted, less variable - and thus less likely to be swayed by products' effects. Thus, we argue that despite a pervasive tendency for self-assessments to be self-serving (Alicke 1985; Dunning, Heath, and Suls 2004), consumers tend to think that products — which deliver results desired by consumers — will work better for others. That is, when comparing how much benefit of using a white noise machine, or a work productivity app, or a revitalizing energy sports drink stacks up to others' respective usage or consumption, consumers will believe that they receive less benefit, believing that products work less efficaciously for themselves than for others. Formally, we hypothesize:

H1: Consumers believe that the same products are more efficacious for others compared to themselves.

\section{PERCEIVED UNIQUENESS AND PERCEIVED MALLEABILITY}

From the perspective of self-serving perceptions, it is likely that consumers tend to believe they are more unique than others. Uniqueness is a socially desirable trait (Ruvio, Shoham, and Brencic 2008), and people have a tendency to believe they possess socially desirable traits (Pedregon et al. 2012). Studies show that consumers are motivated to maintain a sense of uniqueness when expressing opinions or engaging in behaviors (Berger and Heath 2007; Givi and Galak 2020; Reich, Kupor, and Smith 2018). The display of deviant opinions 
and behaviors is seen as a signal of "strong character, strong convictions, and autonomy" (Simonson and Nowlis 2000, p. 51). In support, people find the idea of being different from others to be intrinsically rewarding (Fromkin and Snyder 1980; Snyder 1992).

As with most self-serving biases, social comparisons may play a role: consumers may not just think they are unique, but more unique than others (Alicke 1985). This could have implications for how well consumers believe products work for themselves as compared to others. Because products are designed for large numbers of consumers, products often follow some degree of a "one size fits all" classification. If consumers view themselves as more unique than others, and different from "all," then they may assume products will not work as well for them.

For products that contain multiple versions or categories, such as clothing and its respective sizes (e.g., XS-XL), consumers tend to reject simplifying themselves into single categories, believing they are represented as possessing multiple, contrasting traits and preferences (cf. self-complexity theory; Linville 1985). Instead of extending this reasoning to others, consumers tend to generalize others into single categories (Barasz, Kim, and John 2016). Indeed, consumers believe they are less knowable than others (Williams and Gilovich 2008), less explainable by science than others (Mata, Simão, and Gouveia 2020), and less classifiable than others - for example, both sensitive and tough (Sande, Goethals, and Radloff 1988). If people believe they possess a greater mixture of incompatible traits than others, they may think a product is ill-equipped to serve their multifaceted selves as well as it serves others. Thus, we hypothesize:

H2: Consumers believe that the same products are less efficacious for themselves than for others because they believe they are more unique than others.

Different literatures support the view that people may consider themselves to be less malleable than others. In the social influence literature, people incorrectly report that they 
would not be susceptible to the conformity manipulations used famously by Solomon Asch (Diekmann et al. 2013). Similarly, research in the communications literature has shown that consumers believe that others are more influenced by advertising than they are (Davison 1983). In this vein, psychology research has found that people believe they are less affected by decision making biases than others (Pronin, Gilovich, and Ross 2004) and less emotionally affected by experiences, such as a flight to Paris (Jung, Moon, and Nelson 2020). People believe their personalities, preferences, and values are relatively stable, especially when forecasting change (Quoidbach, Gilbert, and Wilson 2013). Indeed, when making choices, people choose more variety for others (Ratner and Kahn 2002), as if believing that others' preferences are more subject to variation than their own.

A perceived difference in the efficacy of products for oneself versus others might also stem from an asymmetry between perceptions of one's own changes versus others' changes. To illustrate, when people try to lose weight, the perceived change they see in their own body might be rather modest. People may frequently check on their progress, and thus the small changes that occur in between frequent judgments go relatively unnoticed. However, when someone else's weight changes, their loss or gain could seem greater because interactions with others are less frequent compared to the daily judgments people make of themselves. Thus, a perceived difference in the efficacy of products for oneself versus others might also stem from an overgeneralized observable asymmetry between people's perceptions of their own changes versus others' changes. Altogether, people may think that others are more malleable than they are. Thus, we hypothesize:

H3: Consumers believe that the same products are less efficacious for themselves than for others because they believe they are less malleable than others.

\section{OVERVIEW OF STUDIES}


In 15 studies (including nine pre-registered studies and five studies located in the web appendix), we show that people think products work better for others (see table 1). In theoretical terms, we demonstrate why this effect occurs (and why it does not). In doing so, we contribute to the heretofore separate literatures on perceived product efficacy and selfother biases in consumer research. We introduce to the literature two novel biases, self-other differences in perceived uniqueness and perceived malleability, that produce a third novel bias, perceived product efficacy.

In empirical terms, we conducted studies with stimulus sampling and linear mixed effects models (LMEM). These methods, rare in consumer behavior research, provide a conservative test of our predictions by accounting for the random stimulus variation that is typical yet often ignored in experimental data (for a discussion, see Judd, Westfall, and Kenny 2012). In addition, we conducted tests of process by separately manipulating both putative mediators, perceived uniqueness and malleability (using the causal chain method), and testing each in a statistical parallel mediation pathway (using the bootstrapping method).

In practical terms, we investigated two downstream consequences of perceiving that others benefit more from products (what product and how much of it people choose for others); and we tested seven potential moderating factors of the effect, including product factors (e.g., product usefulness) and social factors (e.g., self-other closeness). The web appendix contains additional studies aimed at reinforcing our evidence and testing alternative explanations. All data and materials are available at: https://tinyurl.com/y8cpay8w. 


\section{TABLE 1: SUMMARY OF FINDINGS}

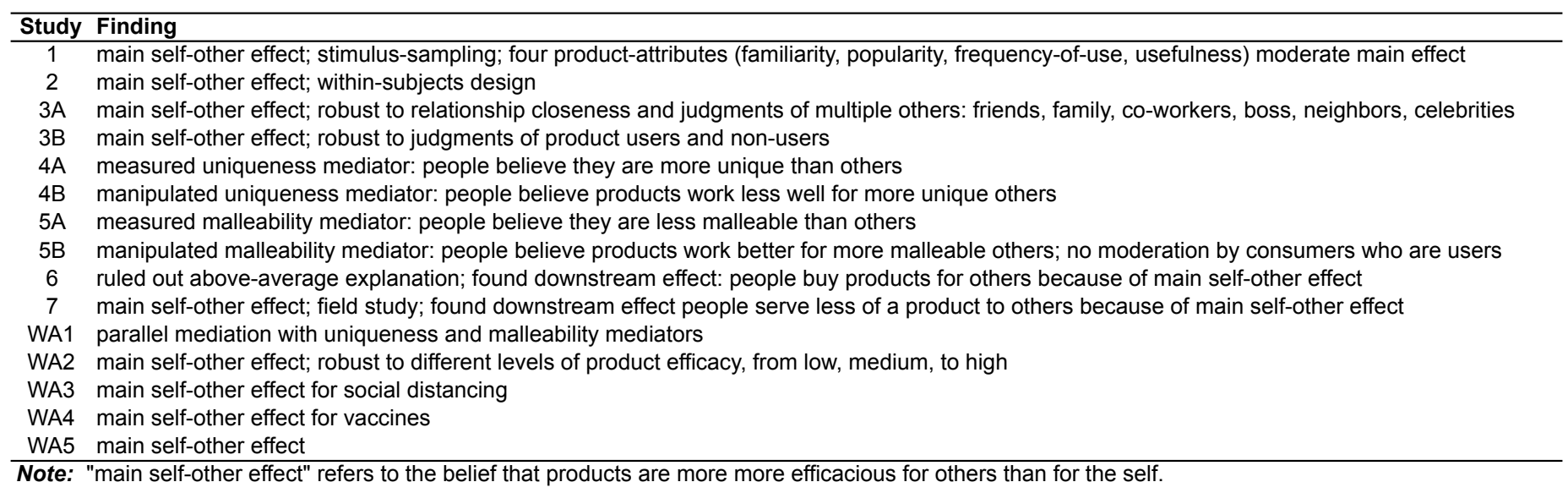

\section{STUDY 1: ROBUSTNESS OF THE BASIC EFFECT}

In study 1 (pre-registered, https://aspredicted.org/blind.php? $\mathrm{x}=\mathrm{dr} 9 \mathrm{p} 9 \mathrm{r}$ ), we tested if participants perceive that the same products are more efficacious for others than for themselves. We adopted a "participants-within-condition" design (Westfall, Kenny and Judd 2014, p. 9), in which participants are nested within condition and products are crossed with conditions. In this design, both "participant" and "product" are random factors, whereas the "experimental condition" is a fixed factor. By testing multiple and diverse products, and treating the product stimuli as a random factor, we can assess whether the predicted self-other difference will generalize to the population of all products (Brauer and Curtin 2018; Judd et al. 2012), which helps ascertain the external validity of our findings. When stimuli are treated as fixed factors, as they often are in consumer behavior research, the conclusions can only safely be made about the stimuli that are specifically tested (Fontenelle, Phillips, and Lane 1985; Judd et al. 2012; Wells and Windschitl 1999). However, with our approach, we can assess the extent to which the predicted self-other difference in perceived product efficacy will generalize not only to participants but also to products. 
Method

We invited all 234 students of an undergraduate marketing class in the United States to participate in our study. We received 225 participants $\left(89\right.$ females, $M_{\text {age }}=19.87, S D_{\text {age }}=1.15$ ) and randomly assigned each into one of two judgment-target conditions (self vs. other). In the “self" condition, we asked participants to evaluate 25 products' efficacy for themselves; in the "other" condition, we asked participants to evaluate the same 25 products' efficacy for others. Two measures, per product, were used to assess perceived product efficacy (see Appendix A for products and measures; the order of products was randomized). As an example, for moisturizer, we asked participants for their levels of agreement to "using a moisturizer will help to hydrate [my / other people's] skin" and "[my/other people's] skin will be hydrated quickly after using a moisturizer." Participants responded to the items from 1 (strongly disagree) to 7 (strongly agree); their responses were averaged. We included an attention check, which all participants passed.

We used 25 different product stimuli to achieve reasonable power for the subsequent analysis. In this study, because "product" is treated as a random factor, the number of product stimuli is as important as the number of participants (Westfall et al. 2014). If only a few product stimuli are tested, a study will not have enough statistical power to detect a reliable effect. For our participants-within-condition design, Westfall et al. (2014) suggest that to achieve reasonable power, the number of stimuli needs to be at least 16 . Testing 25 different product stimuli is therefore sufficient.

As pre-registered, we used a linear mixed effects model (LMEM) to analyze the data. Recent research has suggested that LMEM is an appropriate analytic method for testing experimental effects when multiple random factors are involved because it allows researchers to specify the corresponding (often present, though ignored) random effect structure in 
experimental data (Barr, Levy, Sheepers and Tily 2013; Brauer and Curtin 2018; Judd, Westfall and Kenny 2017). As we noted, in this study, both "participant" and "product" are random factors, and the condition "judgment-target" is a fixed factor. These three factors create three types of non-independence in the data: the ratings could be more similar (1) because they were made by the same participant; (2) because they were made for the same product; and (3) because they were made for the same product in the same condition of judgment-target. Not accounting for this triple source of non-independence results in increased Type-I error (Judd et al. 2012), yet LMEM with a random effect structure resolves this error-inflation issue. Following Barr et al.'s (2013) suggestions, we included a byparticipant random intercept to control for the non-independence caused by participants and a by-product random intercept to control for the non-independence caused by products. In addition, Barr et al. (2013) suggest that a by-product random slope for any predictor that varies within products should be included. Thus, we also added a by-product random slope to capture the non-independence caused by the judgment-target condition and "product" factor. Adding these two random intercepts, plus the random slope in our LMEM, enables us to account for the triple source of non-independence.

Results

We averaged participants' responses to the two efficacy items to create one perceived efficacy measure per product (products' $\alpha$ s ranged from .47 to .91 ). In support of hypothesis 1, we found participants believed that products were more efficacious for others $(M=4.93)$ than for themselves $(M=4.75), F(1,137.09)=4.46, p=0.04, d=0.13$. We conducted a second analysis among only products with $\alpha$ greater than .70, the typical cut-off for the $\alpha$ agreement-level. Of the 25 products, 21 products' as exceeded .70. With this analysis, we 
found a virtually identical effect; participants believed that products were more efficacious for others $(M=4.88)$ than for themselves $(M=4.65), F(1,123.47)=6.01, p=0.02, d=0.16$.

Note, we do not report the omnibus standard deviations because LMEM is not a variance-

based analysis; accordingly, in LMEM, a standard deviation does not provide an interpretable statistic (though, see table 2 for descriptive statistics per product and condition).

TABLE 2: DESCRIPTIVE STATISTICS OF PERCEIVED PRODUCT EFFICACY

PER CONDITION (STUDY 1)

\begin{tabular}{|c|c|c|c|c|c|c|c|}
\hline Product & $\begin{array}{c}\text { Self } \\
(\mathrm{SD})\end{array}$ & $\begin{array}{c}\text { Others } \\
\text { (SD) }\end{array}$ & $\begin{array}{c}\text { Cohen's } \\
d^{\text {a }}\end{array}$ & Familiarity & Popularity & $\begin{array}{c}\text { Frequency } \\
\text { of Use }\end{array}$ & Usefulness \\
\hline Moisturizer & $5.89(1.02)$ & $5.71(0.94)$ & $(0.18)$ & 5.86 & 5.89 & 5.71 & 5.68 \\
\hline Productivity app & $4.65(1.26)$ & $4.84(1.05)$ & 0.17 & 4.36 & 4.42 & 4.27 & 5.07 \\
\hline Relaxation lamp & 3.95 (1.39) & $4.38(1.20)$ & 0.33 & 3.02 & 3.31 & 3.09 & 3.61 \\
\hline White noise sound machine & $4.10(1.54)$ & $4.81(1.08)$ & 0.54 & 4.25 & 3.78 & 3.58 & 4.15 \\
\hline Coloring book & $3.68(1.43)$ & $4.28(1.39)$ & 0.42 & 5.76 & 4.94 & 4.07 & 3.63 \\
\hline Percussion massage gun & $5.43(1.22)$ & $5.26(1.00)$ & $(0.16)$ & 3.00 & 3.35 & 2.90 & 3.76 \\
\hline Energy lamp & $3.63(1.40)$ & $4.16(1.20)$ & 0.40 & 2.87 & 3.22 & 2.98 & 3.39 \\
\hline Deep sleep pillow spray & $3.93(1.38)$ & $4.20(1.25)$ & 0.21 & 2.82 & 3.03 & 2.98 & 3.19 \\
\hline Energy drink & $5.29(1.45)$ & $5.34(0.87)$ & 0.04 & 5.82 & 6.02 & 5.29 & 4.55 \\
\hline Sunscreen & $6.01(1.10)$ & $5.96(0.98)$ & $(0.06)$ & 6.05 & 5.73 & 5.40 & 5.85 \\
\hline Plant-based oil extract & $4.36(1.38)$ & $4.51(1.24)$ & 0.11 & 3.90 & 4.06 & 3.76 & 3.86 \\
\hline Bronzing cream & $4.70(1.48)$ & $4.96(1.22)$ & 0.20 & 3.80 & 4.00 & 3.55 & 3.04 \\
\hline Granola bar & $5.08(1.38)$ & $5.18(1.17)$ & 0.08 & 5.96 & 5.56 & 5.29 & 4.98 \\
\hline E-cigarette & $5.36(1.17)$ & $5.54(1.03)$ & 0.17 & 4.69 & 4.92 & 4.52 & 2.90 \\
\hline Aromatherapy diffuser & $4.20(1.49)$ & $4.55(1.14)$ & 0.27 & 4.30 & 4.15 & 3.80 & 3.80 \\
\hline Elderberry & 4.19 (1.12) & $4.42(1.00)$ & 0.22 & 3.16 & 3.14 & 2.96 & 3.42 \\
\hline Sports drink & $4.80(1.40)$ & $4.99(1.04)$ & 0.15 & 5.77 & 5.83 & 5.34 & 4.65 \\
\hline Online courses & $4.67(1.34)$ & $4.76(1.30)$ & 0.07 & 4.48 & 4.40 & 4.21 & 5.35 \\
\hline Language-learning app & $4.92(1.14)$ & $4.86(1.07)$ & $(0.06)$ & 4.83 & 4.63 & 4.14 & 5.58 \\
\hline Vocabulary-learning app & $5.06(1.07)$ & $5.11(1.05)$ & 0.05 & 4.00 & 4.04 & 3.74 & 5.19 \\
\hline Self-help book & $4.40(1.18)$ & $4.53(1.28)$ & 0.10 & 4.89 & 4.81 & 4.27 & 4.71 \\
\hline Tempurpedic mattress & $4.81(1.25)$ & $5.06(0.95)$ & 0.22 & 4.60 & 4.79 & 4.40 & 5.05 \\
\hline Steroids & $4.86(1.54)$ & $5.34(1.18)$ & 0.35 & 3.98 & 3.85 & 3.44 & 3.45 \\
\hline Cooking lessons & $5.62(1.05)$ & $5.38(1.00)$ & $(0.24)$ & 4.93 & 4.72 & 4.17 & 5.41 \\
\hline Whitening strip & $5.07(0.98)$ & $5.03(0.98)$ & $(0.04)$ & 5.07 & 5.18 & 4.57 & 4.64 \\
\hline
\end{tabular}

${ }^{a}$ Cohen's $d$ s of negative values are in parentheses.

Discussion 
By adopting a participants-within-condition design and applying LMEM to analyze the data, we demonstrated that the self-other difference in perceived product efficacy is robust; it generalizes across individuals and products.

Because we examined 25 products, our study enables us to test if the self-other difference is moderated by different product attributes. Specifically, we conducted a preregistered post-test (https://aspredicted.org/blind.php? $\mathrm{x}=\mathrm{ex} 2 \mathrm{nk} 6$ ) in which we polled 316 participants from Amazon Mechanical Turk (MTurk) to rate each product on four dimensions: familiarity ("How familiar would you rate the following products?);" popularity ("How popular would you rate the following products?"); frequency of use (“How often would you say the following products are used?"); and usefulness (“How useful would you rate the following products?"). Participants responded from 1 (not at all) to 7 (very). We then averaged across the judgments participants made for each respective dimension (per product), which furnished a respective average dimension rating for each product (see table 2 for product ratings). Next, we individually regressed the self-other difference in perceived product efficacy on each product rating. In doing so, these analyses test whether the size of the self-other difference in perceived product efficacy is related to the different product dimensions, such as a product's familiarity. Because the dependent variable is the size of the self-other effect, these regressions test if the respective product dimensions moderate the selfother effect - that is, which kinds of products demonstrate a larger or smaller self-other difference in perceived product efficacy. For each product rating, we found an inverse relationship between the product rating and the self-other difference in perceived product efficacy. Thus, the results show that the self-other difference in perceived product efficacy is moderated by products' popularity $(b=-0.09, S E=0.04, p=.029)$, frequency of use $(b=-$ $0.10, S E=0.04, p=.027)$, usefulness $(b=-0.13, S E=0.04, p=.001)$, and to a lesser extent, 
familiarity $(b=-0.06, S E=0.04, p=.096)$. For example, as a product decreases in popularity, the self-other difference in perceived product efficacy increases.

In subsequent studies (studies 2-7, WA1-5), we attempt to determine what explains the self-other difference in perceived product efficacy, whether this difference manifests among multiple and unique judgment-targets, and what consequences it could have for behavior. Given that the subsequent studies focus less on the effect's generalizability (i.e., the motivation is not to show that the findings are robust across products, as was the case here in study 1), we no longer treat "product" as a random factor. Instead, the only random factor in the following studies is the "participant" factor. As Judd et al. (2017) point out, when a study has only one random factor, LMEM produces the same results as standard regression-based approaches (e.g., ANOVA, $t$ test). Hence, because study 1 finds that the effect is indeed robust across products, for simplicity and ease of understanding, we use standard regressionbased approaches in the following studies.

\section{STUDY 2: WITHIN-SUBJECTS COMPARATIVE DESIGN}

Study 2 (pre-registered, http://aspredicted.org/blind.php? $\mathrm{x}=\mathrm{c} 5 \mathrm{rw} 8 \mathrm{j}$ ) examines the selfother difference using a conservative test in which the judgment-target factor (self vs. other) is a within-subjects factor. The test is conservative because, unlike a between-subjects design in which participants assess products for themselves or others, this study allows participants to simultaneously assess products for themselves and others. Thus, participants might recognize that it would be irrational or inconsistent to asymmetrically believe that products work better for others.

Method 
We recruited 600 participants from MTurk and received 601 participants (270 females, $M_{\text {age }}=39.05, S D_{\text {age }}=12.06$ ). We presented participants with four products (stomach relief medicine, bronzing cream, sleeping pills, an e-cigarette) with four respective effects (helping with stomach pain, helping to suntan, helping to sleep, damaging one's health), in randomized order. For each product, we asked participants how much it would trigger its effect for themselves in comparison to the average American. Participants responded on a scale from 1 (definitely more effective for me) to 4 (equally effective for me and for the average American) to 7 (definitely more effective for the average American). Participants used a slider scale with a midpoint indicating that the target product is as effective for others as it is for themselves, with endpoints indicating that the product is more effective for the self or more effective for the average American.

Results and Discussion

We submitted participants' responses to the four product ratings to a one-sample $t$ test that compares participants' perceived efficacy rating per product with the midpoint value, 4, which is the point that indicates that a product is equally effective for the average American and the self. For each product, we found a significant self-other difference, suggesting that when directly comparing judgments of products' efficacy for the self and others, participants believed that products were more efficacious for others than for themselves: specifically, for stomach relief medicine $(M=4.45, S D=1.17, t(600)=9.42, p<.001, d=0.38)$; bronzing cream $(M=4.72, S D=1.33, t(600)=13.27, p<.001, d=0.54)$; sleeping pills $(M=4.62, S D$ $=1.29, t(600)=11.70, p<.001, d=0.48) ;$ and an e-cigarette $(M=4.51, S D=1.40, t(600)=$ 8.96, $p<.001, d=0.37$ ). Given that participants could provide seemingly unbiased responses 
in this study, these effect sizes are surprising. Making judgments and choices in a "joint evaluation" mode, as tested here, can have a debiasing effect (Bazerman et al. 2011; Ordóñez et al. 1995), yet we still observed the self-other difference. Moreover, study 2 showed that the self-other difference persisted when participants compared themselves with an average American. One might think that products would work in an average way for an average American. But our participants nonetheless believed that products work less well for themselves, even against an average other.

\section{STUDIES 3A AND 3B: MULTIPLE OTHERS}

In this pair of studies, we sought to test the effect among different kinds of judgmenttarget others, from friends to co-workers to celebrities (study 3A). We also tested judgmenttargets specifically described as product users or non-users (study 3B). When thinking about how well products work for others, consumers may imagine those others to be product users. If so, the effect could be chalked up to an artifact of our studies' materials, which may be prompting participants to imagine others whom they are judging as users of the products in question and therefore as people who benefit from using the products (or else they would not continue to buy them). Thus, we manipulated the usership of judgment-targets to test whether the self-other bias is limited to perceived product users or to people more broadly. Second, we measured the relationship closeness of judgment-targets to the self, which allowed us to test if self-other closeness influences the asymmetrical effect of perceived product efficacy. As closeness to others increases, the bias could change in kind - for example, consumers may know more about closer others and may therefore state with more accuracy how much a product would affect them. 
Method

In study 3A (pre-registered, https://aspredicted.org/blind.php? $\mathrm{x}=\mathrm{y} 5 \mathrm{ec} 8 \mathrm{x}$ ), we recruited 1,050 participants from MTurk and received 1,113 participants. We randomly assigned participants to one of seven conditions and asked them to answer two questions concerning the efficacy of a device designed to improve mood. The judgment-target varied by condition: participants made product efficacy judgments for the self, a friend, a co-worker, a boss, a distant family member, a neighbor, or a celebrity. For example, in the "self" condition, participants answered, "How much do you think a device that is supposed to improve your mood would help you?" and "How quickly do you think your mood would improve after using a device that is supposed to improve your mood?" By contrast, in the "friend" condition, participants answered the same two questions for a friend. All participants responded to the questions on a scale ranging from 1 (not at all) to 7 (a lot, very quickly; per question respectively). In addition, we asked participants how close the imagined judgmenttarget is to the self on a scale ranging from 1 (not at all) to 7 (very close).

In study 3B (pre-registered, https://aspredicted.org/blind.php? $\mathrm{x}=\mathrm{ik} 5 \mathrm{dq} 9$ ), we recruited 600 participants from MTurk and received 610 participants. We randomly assigned participants to one of four conditions and asked them to answer the first question from study 3A concerning the efficacy of a device that is designed to improve mood (as pre-registered). As in study 3A, the judgment-target varied by condition: participants made product efficacyjudgments for the self, other, other user, or other non-user. For example, in the "other nonuser" condition, participants answered the question, "Thinking of others who have never used a device that improves their mood, how much do you think using the device would help them?" 
Results

In study 3A, we averaged participants' responses to the two items that assess the dependent variable, perceived product efficacy $(\alpha=.83)$. We conducted a one-way ANOVA among the seven conditions on perceived product efficacy and found a significant effect, $F(6$, $1102)=5.88, p<.001, \eta^{2}=0.031-$ a difference that was qualitatively the same when we ran a one-way ANCOVA with self-other closeness as a covariate, $F(6,1100)=19.60, p<.001, \eta^{2}$ $=0.088$. In this analysis, we found that self-other closeness had a positive effect on perceived product efficacy, $b=0.28, S E=0.03, p<.001$, indicating that closeness to the judgmenttarget (regardless of whether the target is a friend or a celebrity, for example) influenced how much products were thought to work for others.

Next, we compared perceived product efficacy in the "self" condition with each of the other six judgment-target conditions, while controlling for the significant effect of self-other closeness. Because we conducted six separate analyses, we ran Tukey tests that adjust for multiple pairwise comparisons. Encouragingly, with this conservative test, we found that perceived efficacy was significantly lower in the "self" condition $(M=3.19, S D=1.74)$ as compared to every other judgment-target condition, all $p \mathrm{~s}<.001, d s>0.74$ (see figure 1).

In study 3B, we conducted a one-way ANOVA among the four conditions on perceived product efficacy and found a significant effect, $F(3,606)=5.70, p<.001, \eta^{2}=$ 0.027. As in study $3 \mathrm{~A}$, we compared perceived product efficacy in the "self" condition with each of the other three judgment-target conditions. Because we conducted three separate analyses, we again ran Tukey tests. We found that perceived product efficacy was significantly lower in the "self" condition $(M=4.80, S D=1.53)$ as compared to each other judgment-target (see figure 1): with "other" $(M=5.38, S D=1.28, t(606)=3.81, p<.001, d=$ $0.43)$, with "other user" $(M=5.20, S D=1.23, t(606)=2.64, p=.042, d=0.30)$, and with 
“other non-user" $(M=5.30, S D=1.21, t(606)=3.26, p=.006, d=0.37)$. Of import, there were no significant differences between the three judgment-target other conditions ("other," "other user," and "other non-user"), $F(2,454)=0.77, p=.462$, which suggests that when people think of others, they are indifferent to whether others are users or non-users when making product efficacy judgments.

\section{FIGURE 1: PERCEIVED PRODUCT EFFICACY FOR MULTIPLE JUDGMENT- TARGETS (STUDIES 3A-3B)}

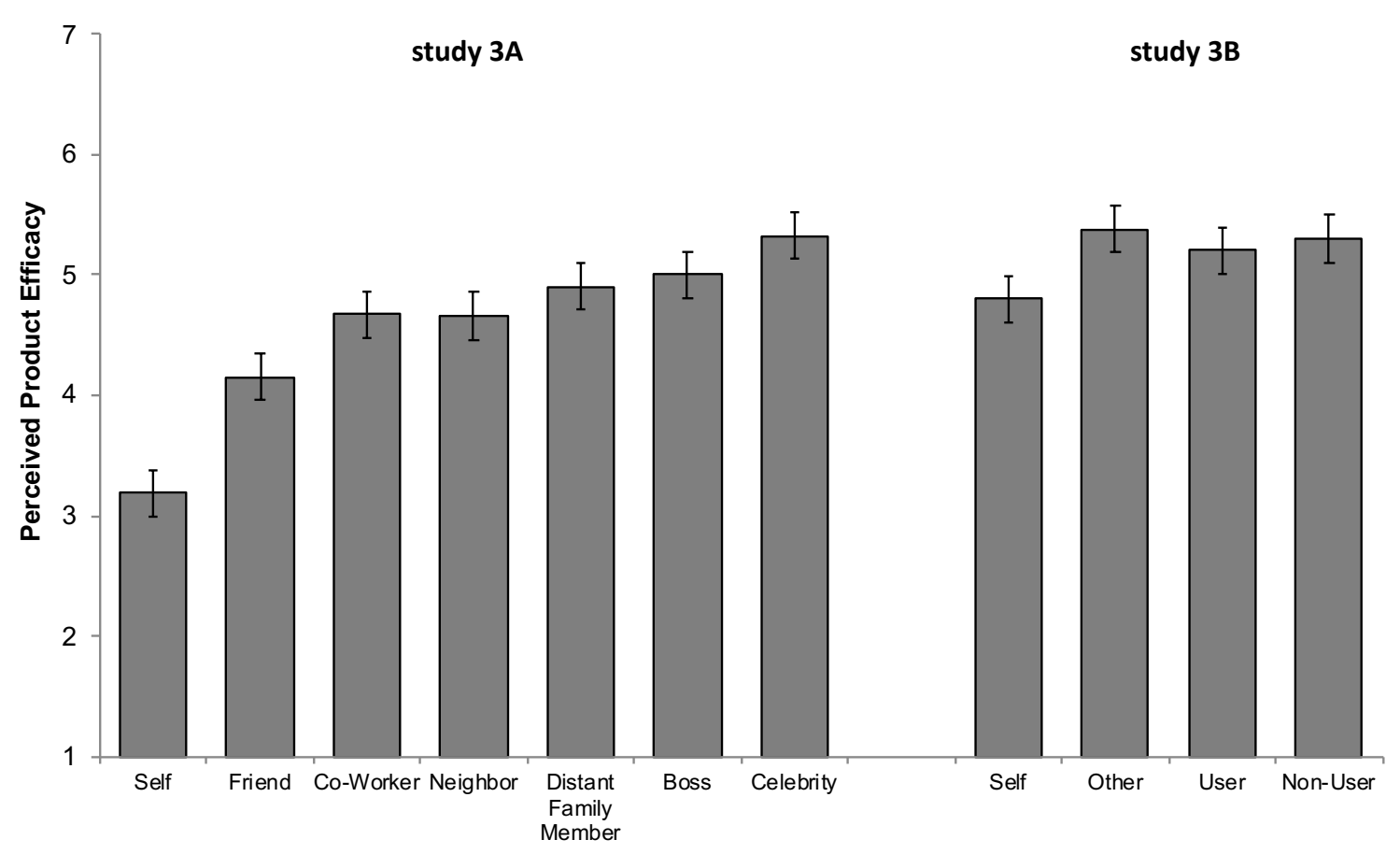

Discussion

In studies $3 \mathrm{~A}$ and $3 \mathrm{~B}$, we found that the predicted self-other difference did not differ by the description of the target-other. The effect was robust to friends, co-workers, neighbors, celebrities, etc.-- even when we controlled for participants' subjective closeness to the target- 
others (study 3A). Furthermore, study 3B found the effect was present regardless of whether participants imagined others as product users or non-users.

Given that we have so far observed an overall net effect in believing that products work better for others, across multiple products in different study designs (studies 1-2) and multiple others (studies 3A-3B), we carried out the following four studies to investigate the underlying mechanisms of this bias by examining whether perceptions of uniqueness and malleability give rise to more favorable assessments of products' efficacy for others than for the self. These studies explain why consumers, on average, believe that products work better for others.

\section{STUDIES 4A AND 4B: MEDIATING ROLE OF PERCEIVED UNIQUENESS}

In this pair of studies, we tested hypothesis 2 , namely whether perceived uniqueness causally mediates the relation between self-other judgment-target and perceived product efficacy. Spencer, Zanna, and Fong (2005) proposed that strong inferences of a causal chain can be made if the independent variable and mediating variable are both manipulated. To that end, self-other judgment-target was manipulated in study $4 \mathrm{~A}$, and perceived uniqueness was manipulated in study 4B. In study 4A, we tested whether people think that they are more unique than others. In study 4B, we manipulated people's perceptions of others' uniqueness and tested if altering the levels of a judgment-target's perceived uniqueness is predictive of how well products will be perceived to work for a respective judgment-target. Taken together, the results of studies $4 \mathrm{~A}$ and $4 \mathrm{~B}$ could indicate that self-other judgment-target influences perceived uniqueness and that perceived uniqueness influences perceived product efficacy.

Method 
In study 4A (preregistered, http://aspredicted.org/blind.php?x=ig369g), we recruited and received 400 participants from MTurk (189 females, $\left.M_{\text {age }}=36.94, S D_{\text {age }}=11.03\right)$. We randomly assigned participants into two conditions (judgment-target: self vs. other), and asked participants to answer three questions that measure perceived uniqueness. In the "self" condition, we asked participants to indicate how unique they are, how distinctive they are, and how much they think they stand out. In the "other" condition, we asked the same three questions but asked participants to judge someone else's uniqueness, namely “MTurker \#161." Participants responded to each question on a scale ranging from 1 (not at all) to 9 (a lot). We included an attention check (“Have you ever had a fatal heart attack?”), which 19 participants failed. We excluded these participants from our analyses (per the preregistration), leaving a sample of 381 participants. The results are statistically indistinguishable from analyses that include the participants who failed the attention check.

In study 4B, we recruited 400 participants and received 406 participants from MTurk (147 females, $\left.M_{\text {age }}=38.48, S D_{\text {age }}=14.41\right)$. We asked participants "How effective would bronzing cream be in helping [you / the average American / a highly unique American] get a suntan?" for three judgment-targets: the self, the average American, and a "highly unique American.” Participants responded to each question on a scale ranging from 1 (not at all) to 7 (very much). We included the same attention check as in study $4 \mathrm{~A} ; 38$ participants failed it. We excluded these participants from our analyses, thus rendering a sample of 368 participants. The following results are statistically indistinguishable from analyses that include the participants who failed the attention check.

Results 
In study 4A, we averaged participants' responses to the three items that assess uniqueness to create the dependent measure, perceived uniqueness $(\alpha=0.89)$. Supporting our prediction, participants believed that they were more unique $(M=6.04, S D=1.70)$ than other people $(M=4.99, S D=2.03), t(379)=5.50, p<0.001, d=0.56$. Hence, the results of study 4A provide empirical evidence for the self-other difference in perceived uniqueness.

In study 4B, to find out whether perceived uniqueness predicts perceived product efficacy, we conducted a repeated-measures ANOVA, which showed a significant effect of judgment-target on perceived product efficacy, $F(2,734)=28.54, p<.001$. With post-hoc comparisons, we found that participants rated the bronzing cream as more effective for the average American $(M=4.72, S D=1.52)$ than for themselves $(M=4.47, S D=1.72), p_{\text {Tukey }}<$ $.001, d=0.21$. Likewise, participants rated the bronzing cream as less effective for the highly unique American $(M=4.25, S D=1.54)$ than for both themselves, $p_{\text {Tukey }}<.001, d=0.18$, and the average American, $p_{\text {Tukey }}<.001, d=0.39$.

\section{STUDIES 5A AND 5B: MEDIATING ROLE OF PERCEIVED MALLEABILITY}

In this pair of studies, we tested hypothesis 3 , namely whether perceived malleability causally mediates the relation between self-other judgment-target and perceived product efficacy. Using the same approach as in studies 4A and 4B, we employed the causal chain method by manipulating and testing the effect of self-other judgment-target on perceived malleability (study 5A) and of perceived malleability on perceived product efficacy (study 5B). In study 5A, we tested whether people think that others are more malleable than they are themselves. In study 5B, we tested whether altering the levels of a judgment-target's perceived malleability is predictive of how well products will be perceived to work for a respective judgment-target. Taken together, the results of studies $5 \mathrm{~A}$ and $5 \mathrm{~B}$ could indicate 
that self-other judgment-target influences perceived malleability and that perceived malleability influences perceived product efficacy. We also measured self-usership in this study, which allowed us to test a potential moderator-namely, whether the product usership of participants affects how much efficacy they ascribe to products and whether this might alter the self-other difference in perceived product efficacy.

Method

In study 5A, we recruited 200 participants and received 219 participants from MTurk (109 females, $\left.M_{\text {age }}=38.43, S D_{\text {age }}=12.72\right)$. We randomly assigned participants to two conditions (judgment-target: self vs. other) and asked them to answer five questions that measure perceived malleability. In the "self" condition, we asked them to indicate how consistent they believed their emotions, physical health, physical appearance, tastes, and overall state would be in the near future. In the "other" condition, we asked the same five items, but we asked participants to indicate how much they believed other peoples' states would be consistent (e.g., "other people's emotions will change in the near future"). Participants responded to each question on a scale ranging from 1 (extremely disagree) to 9 (extremely agree).

In study 5B (pre-registered, http://aspredicted.org/blind.php? $\mathrm{x}=5 \mathrm{px} 2 \mathrm{wt}$ ), we recruited 600 participants and received 612 participants from MTurk (324 females, $M_{\text {age }}=38.01, S D_{\text {age }}$ $=12.83$ ). We randomly assigned participants to three conditions (judgment-target: self vs. other vs. stoic-other). We asked participants about the perceived efficacy of a coloring book on three items: using a coloring book will help to inspire creativity; using a coloring book can produce a long-lasting effect; and creativity will be boosted quickly after using a coloring book. According to condition, participants were instructed to report the coloring book's 
perceived product efficacy for themselves, for others, or, in the "stoic-other" condition, for someone described as "a resilient person, whose physical condition and emotional state are not easily molded."

We next asked participants to indicate their judgment-targets' perceived malleability on three items: how much they agree that the judgment-target's emotions and physical condition will change in the near future, in addition to the extent the judgment-target will change overall. Participants responded to all measures on a scale ranging from 1 (strongly disagree) to 7 (strongly agree). As a robustness check, we conducted a confirmatory factor analysis on the three malleability items and the three efficacy items. Zhao, Lynch, and Chen (2010) suggested this approach to assess if mediators are sufficiently distinct from outcome measures in a causal chain. If one factor fits the data, then the variables risk measuring the same construct; however, if two factors fit the data, then the measures are distinct. In support of the constructs' differentiation, a two-factor model fit the data very well, CFI $=.996$, $\mathrm{RMSEA}=.045$, whereas a one-factor model failed to fit the data, $\mathrm{CFI}=.654, \mathrm{RMSEA}=.397$. Finally, we also measured product self-usership by asking participants, "Do you use a coloring book?" (with a choice of "yes" or "no"). We included the same attention check as in studies 4A and 4B; 17 participants failed it. We excluded these participants from our analyses (per the pre-registration), leaving a sample of 595 participants. The results are statistically indistinguishable from analyses that include the participants who failed the attention check.

Results

In study $5 \mathrm{~A}$, we averaged participants' responses to the five items that assess malleability to create the dependent measure, perceived malleability $(\alpha=0.72)$. Supporting our hypothesis, participants believed that others were more malleable $(M=5.92, S D=1.13)$ 
than they were themselves $(M=4.95, S D=1.43), t(217)=5.59, p<0.001, d=0.76$. Thus, the results of study $5 \mathrm{~A}$ provide empirical evidence for the self-other difference in perceived malleability.

In study $5 \mathrm{~B}$, to determine if perceived malleability predicts perceived product efficacy, we first checked the perceived malleability manipulation. We averaged participants' scores to the three malleability items $(\alpha=0.89)$. The manipulation was successful; an ANOVA showed a significant effect of judgment-target, $F(2,592)=32.10, p<0.001, \eta^{2}=0.098$. With posthoc comparisons, we found that participants rated themselves as less malleable $(M=5.66, S D$ $=1.74)$ than others $(M=6.19, S D=1.48), p_{\text {Tukey }}=.006, d=0.31$, consistent with the results of study $5 \mathrm{~A}$. We also found that participants rated the stoic-other as less malleable $(M=4.81$, $S D=1.90)$ as compared to participants' rating of their own malleability, $p_{\text {Tukey }}<.001, d=$ 0.49 , and others' malleability, $p_{\text {Tukey }}<.001, d=0.80$.

Next, we checked if the manipulation of a judgment-target's perceived malleability affects the product efficacy that participants render on their judgment-target. We averaged participants' scores to the three product efficacy items $(\alpha=0.92)$, and conducted an ANOVA which showed a significant effect of judgment-target, $F(2,592)=17.70, p<0.001, \eta^{2}=$ 0.056. Consistent with the perceived malleability findings, the post-hoc comparisons show that participants rated the coloring book as more effective for others $(M=6.49, S D=1.61)$ than for themselves $(M=5.90, S D=1.90), p_{\text {Tukey }}<.001, d=0.33$. However, participants rated the coloring book as less effective for stoic-others $(M=5.39, S D=1.94)$ than for both themselves, $p_{\text {Tukey }}<.001, d=0.28$, and others, $p_{\text {Tukey }}<.001, d=0.60$.

Of import, we did not find that product self-usership had a moderating effect on the results. In our sample, 213 of 595 participants (35.8\%) indicated that they used a coloring book. We conducted a 2 (user vs. non-user) $\times 3$ (judgment-target) ANOVA on perceived product efficacy. Both of the main effects were significant: users indicated the coloring book 
to have more efficacy $(M=6.93, S D=1.41)$ than non-users $\operatorname{did}(M=5.37, S D=1.87), F(1$, $589)=119.25, p<.001, \eta^{2}=0.159$; as above, the coloring book was thought to have different efficacy, according to judgment-target, $F(2,589)=20.30, p<.001, \eta^{2}=0.054$ (the descriptive statistics are the same as reported above; more efficacy for others than the self, but less for stoic-others). Of import, the interaction was not significant, suggesting that for a coloring book, self-usership did not change the self-other difference in judgments of its efficacy, $F(2,589)=0.77, p=.463, \eta^{2}=0.002$.

\section{SUMMARY OF PROCESS EVIDENCE}

Taken together, studies 4A-4B and 5A-5B locate perceived uniqueness and perceived malleability as mediators in the causal chain between self-other judgment-target and perceived product efficacy. Going a step further, we conducted an additional pre-registered study (study WA1; see web appendix for details and results) that assesses the mediations of perceived uniqueness and malleability in a different manner. Extending studies 4A-4B and $5 \mathrm{~A}-5 \mathrm{~B}$, we tested the mediators in tandem in study WA1 using a parallel process-bymediation design and analysis. This study sheds more light on the pathways between judgment-target and perceived product efficacy. For example, in studies $4 \mathrm{~A}$ and $5 \mathrm{~A}$, we found that the self-other effect of judgment-target on malleability was greater than the respective self-other effect on uniqueness (respectively, $d \mathrm{~s}=0.76$ vs. 0.56 ). Therefore, we might expect that perceptions of malleability possess a more influential role in generating or altering product efficacy judgments than perceptions of uniqueness. Thus, study WA1 not only provides additional evidence by examining both mediators at once (in parallel) in a mediationby-measurement design, but allows us to compare the separate effects of each mediator on product efficacy perceptions (which we found to be statistically equivalent). 
Notably, because we measured perceived malleability and perceived product efficacy in study $5 \mathrm{~B}$, we were able to test for both causal and statistical mediation in this study. In lock-step with the causal chain approach, we found that the self-other difference in perceived product efficacy was statistically mediated by the self-other difference in perceived malleability for both the self-vs.-other test, $b=-0.16, S E=0.05,95 \% \mathrm{CI}=[-0.26,-0.05]$, and self-vs.-stoic-other test, $b=0.38, S E=0.09,95 \% \mathrm{CI}=[0.20,0.57]$.

In summary, the results of study WA1 complement the causal chain findings from studies 4A-4B and 5A-5B. In all, we have evidence of both mediators using two different designs for assessing process: a mediation-by-moderation analysis in which we manipulated judgment-target and both mediators using the causal chain approach (in studies 4A-4B and 5A-5B); and a mediation-by-measurement analysis in which we measured and analyzed the mediators in parallel and individually, using a bootstrapping approach (in study WA1). With these different analyses and methods (by separately manipulating and measuring each mediator), and the convergent results that they have rendered, we can conclude that the selfother uniqueness and malleability biases play an important role in asymmetrical perceptions of product efficacy.

\section{STUDY 6: AN ALTERNATIVE EXPLANATION (ABOVE-AVERAGE EFFECT)}

Having uncovered two explanations for the self-other difference in perceived product efficacy in five studies (studies 4A-4B, 5A-5B, and WA1), we next sought to test an explanation based on the above-average effect (Alicke 1985). Specifically, the results we have documented could also be due to consumers believing that they need products less than others do. That is, if they believe they would benefit less from using a moisturizer because their skin 
is better than others' skin, they would view products that improve skin as having a smaller effect on themselves than on others.

If the self-other effect manifests because consumers believe they need a product's benefits less than others, then when we increase participants' own level of product need, they should perceive that a product will work better for themselves than for others. In study 6 , we tested for this account and also examined a downstream effect of believing that products work better for others: whether people would buy the product for themselves or others.

Method

In study 6 (pre-registered, https://aspredicted.org/blind.php?x=26pi84), we invited all 770 students of an undergraduate marketing class in the United States to participate in our study and received 606 participants. We manipulated whether participants would feel below or above average on their reading comprehension, then measured how efficacious they believe a reading aid would be for themselves versus others. Specifically, we altered participants' beliefs about their reading comprehension using the false-feedback paradigm (e.g., Ross, Lepper, and Hubbard 1975) — a method that changes people's beliefs about themselves (e.g., their skills). False-feedback inductions typically contain a quiz that participants take that ostensibly measures a skill or aptitude. Following the quiz, participants are randomly assigned a grade that indicates that they are below or above average on the purportedly measured skill or aptitude.

Using the false-feedback approach, we told participants they were taking part in a study of reading comprehension and that their task was to identify, from a list of 130 names, which were actual writers of books, magazine articles, and/or newspaper columns (the "Author Recognition Test," a verified test of reading skills by Acheson, Wells, and 
MacDonald 2008). After they finished the test, we gave them a false grade. By random assignment, some participants were told that their reading comprehension was "below average, in the 39th percentile," whereas others were told it was "above average, in the 84th percentile."

Next, we asked participants to assess the efficacy of a reading aid, in the form of a pill, for themselves or for others. Specifically, we asked participants, according to condition, "How much do you think taking a pill that is supposed to improve [your] reading comprehension would help [you / other people]?" "How quickly do you think [your / other people's] reading comprehension could improve after taking a month-long course of reading comprehension pills?" and "How effective would taking a reading comprehension pill change [your / other people's] reading comprehension?" Participants responded from 1 (not at all) to 7 (a lot, very quickly, very effectively; per question respectively). Next, we asked, "Would you buy a reading comprehension pill for [yourself / someone else]?" ("yes" or "no"). We then asked participants to answer four items included as control variables: "How new would you say are reading comprehension pills?" "How familiar are you with reading comprehension pills?" "How popular are reading comprehension pills?" and "How much do you think people use reading comprehension pills?" Participants responded from 1 (not at all) to 7 (extremely). Finally, we asked participants to respond to a manipulation check concerning the false feedback: "How good is your reading comprehension?" Participants responded from 1 (below average) to 7 (above average).

In sum, study 6 employed a 2 (judgment-target: self vs. other) $\times 2$ (self-perceived skill-level: below- vs. above-average) design that allowed us to test whether people continue to think that a product works better for others even when they believe they are worse than others on the dimension that the relevant product aims to improve. 
Results

To determine if the false-feedback manipulation was successful, we conducted a 2 (judgment-target) $\times 2$ (skill-level) ANOVA on the manipulation check and found that participants in the below-average condition reported that their reading comprehension was worse than others' $(M=3.57, S D=1.45)$ as compared to participants in the above-average condition $(M=4.88, S D=1.31), F(1,601)=135.36, p<.001, d=0.95$ (no other effects in the ANOVA were significant). Participants in the below-average condition rated their reading comprehension significantly below the midpoint on the scale, $t(302)=5.11, p<.001, d=$ 0.29 .

Having established that participants in the below-average condition believed their reading skills to be below average, we conducted the main test: a 2 (judgment-target) $\times 2$ (skill-level) ANOVA on the dependent variable, the average score for the three items that measured perceived product efficacy $(\alpha=.87)$. We found only a main effect of judgmenttarget, such that participants indicated that the reading aid would work better for others $(M=$ 4.37, $S D=1.33)$ than for themselves $(M=3.76, S D=1.57), F(1,602)=26.80, p<.001, d=$ 0.42 (see figure 2). Of import, the interaction was not significant, $F(1,602)=0.03, p=.857$ (nor was the main effect of skill-level, though it was marginal, $F(1,602)=2.93, p=.087$ ). This demonstrates that among participants who perceived themselves to be below average on the skill that the product aims to improve on, there was a self-other difference in the product's perceived efficacy $\left(M_{\text {self }}=3.67, S D=1.57\right.$ vs. $\left.M_{\text {other }}=4.26, S D=1.36\right), F(1,301)=12.30, p$ $<.001, d=0.40$. Thus, we can rule out the putative above-average explanation in our results, since it cannot be the case that participants believe that products work better for others because they perceive themselves to have a "leg up" on the skill (or aptitude) that a product is supposed to improve. As we found in study 6, when participants were led to believe they 
would benefit by using the product, owing to their self-perceived below-average productrelated skill-level, they continued to believe the product would positively affect others more.

FIGURE 2: PERCEIVED PRODUCT EFFICACY FOR SELF/OTHER ACCORDING TO SKILL-LEVEL (STUDY 6)

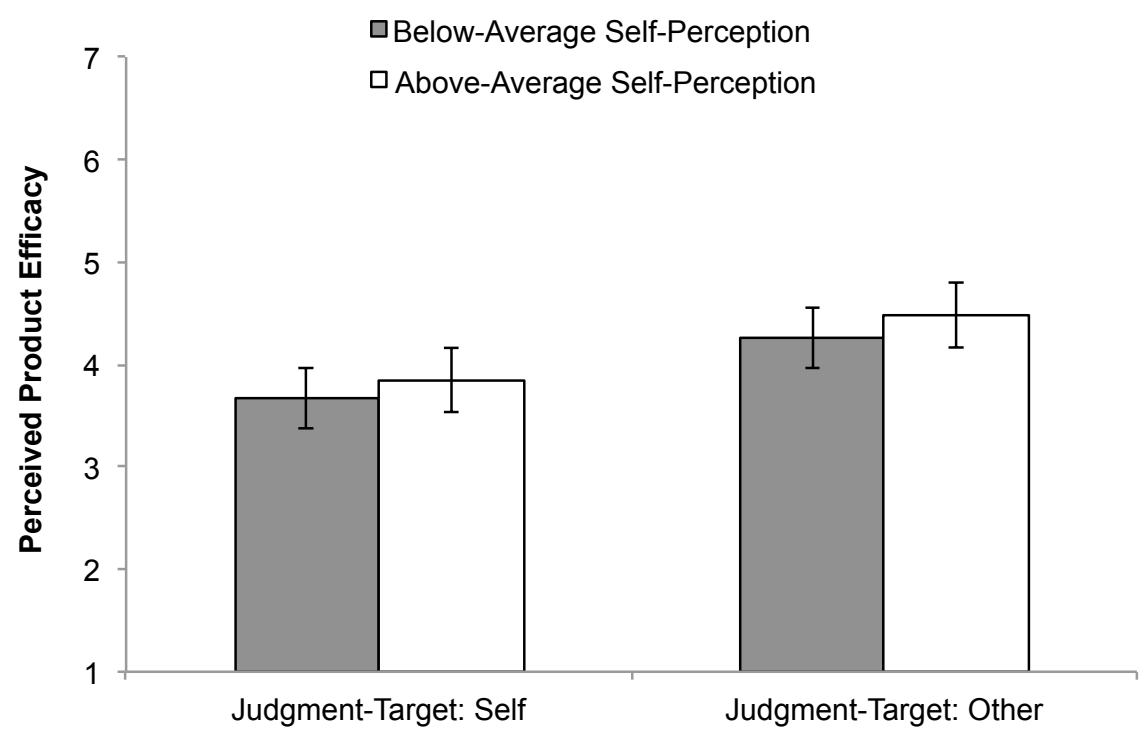

In addition to testing the above-average explanation in this study, we also measured whether participants would buy the reading comprehension pills. Consistent with the selfother difference in perceived product efficacy, we found that participants were more likely to buy them for others $(162 / 301 ; 53.8 \%)$ than for themselves $(98 / 304 ; 32.2 \%), \chi^{2}(1)=28.80, p$ $<.001, w=0.22$ - a pattern consistent with participants in the below-average condition, who were also more likely to buy them for others $(78 / 152 ; 53.1 \%)$ than for themselves $(48 / 151$; $31.8 \%), \chi^{2}(1)=11.90, p<.001, w=0.20$. Offering further support for this downstream effect, the self-other difference in purchase likelihood was directly related to (and mediated by) participants' self-other perception of product efficacy: the relation between judgmenttarget and purchase likelihood was mediated by participants' perceived product efficacy of the pills, $b=0.11, S E=0.02,95 \% \mathrm{CI}=[0.07,0.15]$. 


\section{Discussion}

Plausibly, consumers might believe that products work better for others because they make more self-serving judgments about their own skills (e.g., reading comprehension), aptitudes (e.g., creativity), or health (e.g., skin) — thus believing that the effects of products on themselves will be smaller than for others (a case of diminishing returns). We did not find this to be the case. Even participants who indicated their reading comprehension was lower than that of others still believed that a reading comprehension product would work better for others than for themselves. Of import, this difference (like all the differences reported above) were qualitatively unchanged when the four covariates were included in the analyses, thus indicating that the patterns held when accounting for participants' perceptions of product newness, familiarity, popularity, and frequency of use (for full results, see table 3).

Study 6 also sheds light on whether the self-other difference is the result of anchoring and adjustment processes (Tamir and Mitchell 2013). It may be that consumers think first of a product's efficacy for themselves and adjust upward as though they have a lay-belief that products work better for others. If this were driving the effect, we would expect participants in the above-average condition to make downward adjustments when judging product efficacy for others. We did not find this to be the case, which places some doubt on an anchoring and adjustment mechanism in our findings.

It is important to note that we had planned to exclude participants who spent less than 110 seconds on the "Author Recognition Test" (as indicated in the pre-registration). Of the 606 total participants in our study, 51\% spent less than 110 seconds, suggesting that our exclusion criterion was potentially too strict. That said, even with this criterion, all of the above effects remained significant (for full results, see table 3). This testifies to the strength of 
our results: Even when we removed half of our sample participants, and thus half of our statistical power, the effects were robust to the exclusion.

\section{TABLE 3: RESULTS FOR MAIN ANALYSIS WITH CONTROLS AND EXCLUDED \\ PARTICIPANTS (STUDY 6)}

\begin{tabular}{|c|c|c|c|}
\hline & $\begin{array}{l}\text { Main Effect: } \\
\text { Judgment-Target }\end{array}$ & $\begin{array}{l}\text { Main Effect: } \\
\text { Skill-Level }\end{array}$ & $\begin{array}{c}\text { Interaction: } \\
\text { Judgment-Target } \times \text { Skill-Level }\end{array}$ \\
\hline \multicolumn{4}{|l|}{ Main Analysis } \\
\hline Reading Comprehension Self-Report & $F(1,601)=2.72, p=.10, d=0.13$ & $F(1,601)=135.36, p<.001, d=0.95$ & $F(1,601)=0.45, p=.50, d=0.06$ \\
\hline Perceived Product Efficacy & $F(1,602)=26.80, p<.001, d=0.42$ & $F(1,602)=2.93, p=.09, d=0.14$ & $F(1,602)=0.03, p=.86, d=0.00$ \\
\hline \multicolumn{4}{|l|}{ Analysis with Controls } \\
\hline Reading Comprehension Self-Report & $F(1,595)=1.62, p=.20, d=0.10$ & $F(1,595)=142.34, p<.001, d=0.97$ & $F(1,595)=0.41, p=.52, d=0.06$ \\
\hline Perceived Product Efficacy & $F(1,595)=29.19, p<.001, d=0.44$ & $F(1,595)=3.91, p=.05, d=0.16$ & $F(1,595)=0.08, p=.77, d=0.00$ \\
\hline \multicolumn{4}{|l|}{ Analysis After Excluding Participants } \\
\hline Reading Comprehension Self-Report & $F(1,292)=2.74, p=.10, d=0.19$ & $F(1,292)=5.49, p=.02, d=0.27$ & $F(1,292)=0.11, p=.74, d=0.00$ \\
\hline Perceived Product Efficacy & $F(1,292)=17.61, p<.001, d=0.49$ & $F(1,292)=0.87, p=.35, d=0.11$ & $F(1,292)=0.66, p=.42, d=0.09$ \\
\hline
\end{tabular}

\section{STUDY 7: BEHAVIORAL IMPLICATIONS OF PERCEIVED PRODUCT EFFICACY}

Our final study seeks to further underscore the relevance of perceived product efficacy not just in and of itself, but for other behaviors more generally. Going beyond product efficacy perceptions, study 7 includes another measure of interpersonal choice: how much (of a) product people choose for others. Moreover, we tested for the mediating role of perceived product efficacy on serving others, which allows us to assess an additional downstream implication as a direct result of perceived product efficacy.

Method

We recruited 218 undergraduate business students in France who participated for course extra credit ( 98 females, $M_{\text {age }}=20.26, S D_{\text {age }}=0.97$ ). Like study 2 , this study employed 
a conservative within-subjects design with judgment-target (self vs. other) as the experimental factor in counter-balanced order.

Upon entering a lab, we presented participants with 30 transparent water cups (with a capacity of $30 \mathrm{ml}$. each) and two bowls, one labelled "self" and one labelled "typical." The bowls were randomly placed either to the left or right of participants. We asked participants how many water cups would be required for each judgment-target to completely satisfy their thirst - i.e., their own thirst and a typical participant's thirst — on two sliders anchored from 0 to 30 . We also asked participants how effective one cup and, separately, five cups, would be at satisfying each judgment-target's thirst. Participants responded to these four questions from 1 (not at all) to 7 (very much). Then we asked participants to distribute the number of cups they believed would be required to satisfy each judgment-target's thirst into its corresponding bowl. The amount of water (measured in cups) served by participants was independently verified by a research assistant. By supplying our measure of how much product people serve others as compared to themselves, this number is a laboratory analogue akin to serving food or drink to others.

Results

We first tested our main effect (hypothesis 1) by examining how quenching participants think one small cup of water is and, separately, five small cups, for their own thirst versus someone else's thirst with paired $t$ tests (per the pre-registration). The test was successful for both one cup and five cups. For one cup of water, we found that participants considered it less thirst-quenching for themselves $(M=2.64, S D=1.42)$ than for someone else $(M=3.06, S D=1.41), t(217)=6.10, p<.001, d=0.41$. Likewise, for five cups of water, we found a similar pattern; participants considered five cups of water less thirst-quenching for 
themselves $(M=4.22, S D=1.48)$ than for someone else $(M=4.44, S D=1.46), t(217)=3.85$, $p<.001, d=0.26$.

In light of finding that participants considered the same amount of water to be more thirst-quenching for others than for themselves, we tested (1) if this meant they would serve less water to others than to themselves. In particular, we tested (2) whether participants' thirst-quenching beliefs (about their own and others' water consumption) would explain how much water they would serve to others and themselves.

To answer the first question, we conducted a paired $t$ test on how much water participants would serve others and themselves. We found that participants would serve less water to others $(M=10.44, S D=6.26)$ than to themselves $(M=13.06, S D=6.66), t(217)=$ 7.15, $p<.001, d=0.48$. A non-parametric test confirmed this analysis, Wilcoxon's $W=$ $14412, p<.001$. To answer the second question, we conducted a within-subjects mediation test using the MEMORE macro for SPSS (Montoya and Hayes 2017) and tested whether the perceived quenching-efficacy of one cup of water could account for the relationship between judgment-target and how much water would be served to the judgment-target. Using a bootstrapping procedure, one thousand repeated random samples were taken from the data to compute this indirect effect. We found that the relation between judgment-target and amountserved was mediated by the perceived quenching-efficacy of a cup of water, $b=0.37, S E=$ $0.18,95 \% \mathrm{CI}=[0.04,0.78]$; likewise, we ran the same test with the measure of perceived quenching-efficacy of five cups of water, $b=0.41, S E=0.10,95 \% \mathrm{CI}=[0.22,0.60]$.

Discussion

This study extended our effect to serving choices that people make for others. We showed that participants choosing how much water to serve opted for a higher-volume serving 
for themselves than for others. Further, we showed that perceptions of water thirst-quenching efficacy underlie this effect. At first glance, it could seem as if participants serve themselves more water because they are selfishly motivated to take more resources than they give to others. But this argument does not hold up, given that participants, on average, used fewer cups than were supplied. In other words, there was more than enough water to serve to others and to the self-and no rent-seeking benefit to serving oneself more water. Relatedly, there could be a hospitable norm of serving more to others. We find the opposite effect in our study; this could be because our participants were prompted to think about how much the water would quench others. When the efficacy of others' product consumption is less highlighted or piqued, we might see evidence of participants serving more to others. Finally, a benefit to study 7 is the product that we tested: water, which is reasonably believed to be consumed by everyone. Therefore, consistent with previous studies, we did not find that others' usership (study 3B) or self-usership (study 5B) moderated the self-other difference in perceived product efficacy (a point to which we return in the General Discussion).

\section{GENERAL DISCUSSION}

In 15 studies, we found consumers believed that a wide range of products, with both negative and positive effects, would be more efficacious for others than for themselves. All told, we tested the effect among 6,547 total participants across several changes in procedure, design, and sample characteristics. We used stimulus sampling and within- and betweensubjects designs, and asked different kinds of participants (American and French college students, and MTurkers) to judge different judgment-targets, from friends, co-workers, celebrities, and fellow MTurkers, to users and non-users, to the average American, and to, of course, themselves. We uncovered five moderators for the effect: product familiarity, 
popularity, frequency of use, and usefulness, and closeness with the judgment-target (and we tested two factors that appeared to show no moderating effect: other- and self-usership). We also found evidence for two mediators, which we tested in two ways with the causal chain and bootstrapping approaches. Finally, we ruled out a putative above-average explanation and documented two separate downstream effects, including one conducted in a behavioral study. The breadth of the studies and tests (of robustness, moderators, mechanisms, alternative explanations, and downstream effects) gives us confidence in our findings and conclusions.

Of note, study 1 explored perceptions of products' efficacy using stimulus sampling with data analysed in LMEM, which accounts for multiple types of non-independence in experimental data. This has the benefit of assessing the external validity of our findings. It also introduces a relevant and under-used method to consumer behavior research. The study of products is central to consumer behavior, and marketing researchers ought to be confident that their findings will generalize across product choices and judgments. Testing multiple products and analyzing "product" as a random factor in LMEM helps to assess our findings' generalizability. Typically, field studies are used to test generalizability, but it remains an open question even in most field studies whether the findings would apply to other products or purchases. Using stimulus sampling and LMEM mitigates this issue, and we advise other researchers to consider following suit to test if their findings are robust.

At first blush, our results could be viewed as a regression effect. When people estimate a product possesses lower efficacy for themselves, they might estimate higher product efficacy for others, because, in line with regressive reasoning, they adjust their judgments of a target dimension accordingly: when product efficacy is thought to be low for the self, people potentiate it higher for others. For three reasons, this cannot be the case in our data. First, a regression account assumes that we over-sampled low-efficacy products in our studies (products that the self considers low-efficacy). However, the average baseline efficacy for the 
tested products - i.e., the average self-rating of efficacy for the 49 products tested across studies-was 4.52 (on a 1-7 scale), which is significantly greater than the scale midpoint, 4, $t(48)=4.59, p<.001, d=0.66$ (for efficacy ratings per product, see table WA1). This suggests that we tended to test products with higher-than-midpoint levels of efficacy, which means that if regression were affecting our results, we would have found that people believe products work less well for others. Second, we conducted a quartile analysis of the products that we tested across studies by ranking them according to participants' self-rating of efficacy (in ascending order) and then calculating the average effect size for the self-other difference per quartile (see table WA1). The effect sizes were $d \mathrm{~s}=0.35,0.27,0.18$, and 0.11 , from the bottom to the top quartile, respectively. To be sure, the effect sizes decrease as baseline efficacy ratings increase. This is illustrative of a ceiling effect: as the baseline efficacy rating increases on a Likert scale (e.g., from 4.00 to 6.75 , on a 1-7 scale), the possible maximal selfother difference logically decreases (from 3.00 to 0.25 , on a 1-7 scale). It is noteworthy that even among products that are median-to-high-efficacy (products in the third quartile), the effect size, $d=0.18$, is typical of effects in psychology (Funder and Ozer 2019); for context, a $d=0.18$ effect size is larger than the effect of taking ibuprofen for pain relief. Finally, we conducted a study (study WA2) in which we manipulated products' efficacy as low, medium, or high. For all products, regardless of efficacy level, we found a significant self-other difference. Notably, for the products with the highest efficacy — a "very strong painkiller" (with baseline efficacy $=6.02$, on a 1-7 scale) and a "very strong energy drink" (with baseline efficacy $=5.21$, on a 1-7 scale) $—$ we found large effect sizes, $d s=0.50$ and 0.34 , respectively (for recent discussion on effect sizes, see Funder and Ozer 2019). To wit, each of these three accounts would in itself rule out a regression explanation. By virtue of yielding three different accounts that are at odds with regression, we can be confident that our effects are robust to regression tendencies. 
Theoretical Contributions

Our work contributes to the literature on perceptions of product efficacy. While prior research has identified several determinants of perceived product efficacy (e.g., Chae et al. 2013; Maglio et al. 2020; Van Bergen et al. 2020; Zhu et al. 2012), we added a social component to the literature by showing that product efficacy judgments are sensitive to judgment-target. We found that because people believed products were more efficacious for others, they were more likely to buy a product for others (study 6) and choose less of a product for others (study 7). For consumers, this is a reasonable response: If someone is especially susceptible to the effects of spicy food, it makes little sense to serve them large dollops of hot sauce. In our research, the perceived impact that an option would have on others reasonably affected the kind of option consumers chose for them.

It follows that more attention should be paid to perceived product efficacy: it precipitates a factor upon which all product-related choices may rest. To be sure, before buying a product, consumers typically speculate its efficacy (Olson and Dover 1979). More generally, before making a decision, people typically consider the impact their decision will have - such that the predicted impact of a choice's options will shape which option is ultimately chosen. This is especially the case in decisions involving donations, and the charities selected by potential donors to receive their money. As research has found, would-be donors consider the perceived impact their donation could have, such as whether an organization will use it effectively by extracting "the most" from their donation (Cryder, Loewenstein, and Scheines 2012; Sharma and Morwitz 2016; Smith, Faro, and Burson 2013).

Perceived product efficacy could play a role in other areas of research, including the rich literature on hedonic-utilitarian trade-offs (Dhar and Wertenbroch 2000). In typical 
studies, hedonic product attributes are juxtaposed with utilitarian attributes (such as usefulness), and researchers examine the extent to which consumers prefer more or less indulgence (at the expense of more or fewer utilitarian benefits). When making choices for others, consumers prefer less utilitarian options, choosing to trade off products' functionality for other benefits, research has found. For instance, consumers choose to give less practical gifts to others (Baskin et al. 2014; Rim et al. 2019) and choose more hedonic products for others (Lu, Liu, and Fang 2016). This could suggest that consumers have a blind spot when making choices for others, preferring options that dazzle in the short run but have less usefulness in the long run (Yang and Urminsky 2018). But from a different perspective, based on our findings, consumers may be less concerned about a product's instrumental efficacy (when choosing a product for others) because even a product with lower perceived efficacy will be thought to precipitate a relatively positive effect on others.

In advice giving, this same logic could clarify whether people have a tendency for giving less useful advice at the expense of giving more desirable advice (Danziger, Montal, and Barkan 2012) or more face-saving advice (Apfelbaum, Krendl, and Ambady 2010). Again, this pattern could be due to divergent self-other perceptions of efficacy: if people believe that others will gain more practical benefits from advice, then they may not feel they need to stress these practical benefits as much. As a coda to this point, in a study conducted during the COVID-19 crisis with 210 MTurk participants (study WA3, conducted in March 2020), we tested whether people believe that others' social distancing is more effective than their own. We found they believed it was, $d=0.67, p<.001$. Furthermore, in a separate study of 216 participants (study WA4, conducted in March 2021), we tested if people believe the COVID-19 vaccine is more effective for others than for themselves; again, they believed so, $d$ $=0.68, p<.001$. Together, these results suggest that efficacy perceptions could also form a type of consumer hypocrisy, whereby consumers may advise a course of action to others that 
they may not follow themselves. Going a step further, this might also suggest who is less likely to buy a new product (or engage in social distancing or get vaccinated). In our work, we found that perceived uniqueness and malleability are related to perceived product efficacy. When these beliefs are inversely correlated, such as when a consumer's self-perceived uniqueness is high and malleability is low, they may think that a product (or behavior) will have little effect on the self. On the other hand, when self-perceived uniqueness is low and malleability is high, a consumer may be easily persuaded by a product's effects — a profile that could characterize early adopters.

Perhaps nowhere is perceived efficacy more relevant than in the area of medicine and drugs. As recent as 2016, research found that people thought black people could tolerate more pain than white people. Even medical students and residents believed this, and made different treatment decisions as a result (Hoffman et al. 2016). Similarly, people believe that poor people are less sensitive to pain than rich people (Cheek and Shafir 2020; Summers et al. 2021). In our studies, we found that consumers believed that medical products work better for others - which would imply that they think they personally need more of the same product to receive the same benefits as others. Such a bias may lead consumers to over-medicate themselves, with potential detrimental side effects. In line with Hoffman et al.'s (2016) research, physicians may give their patients more or less of a medicine according to how much they think their patients will be affected by it.

In this vein, research could be conducted on how to correct judgments of product efficacy based on product usership by consumers. Given our studies, it might appear as though when a consumer is rendering judgment on a product they use, there is an enduring self-other difference in perceived product efficacy_-because (1) we did not find a significant interaction in study 5B (indicating similar self-other effects rendered by participants who are users and non-users), and (2) we found a significant effect among a widely-used product in 
study 7, water (something that everyone consumes). However, we caution that it could be premature to conclude that consumers' own product usership has no effect on moderating the self-other difference documented here.

Most studies in consumer psychology do not account for whether study participants are users of the products being tested. However, akin to the research on self-control that often finds divergent effects between dieters and non-dieters (Fishbach, Zhang, and Trope 2010), we might expect a similar divergence between consumers who are product users versus nonusers in studies of consumer behavior. It is difficult to manipulate usership, which, by definition, is self-selected — such that using a self-selected product that one has used for months is reasonably different from using a product for a short time in a laboratory study. Fortunately, usership is easy to measure. For example, we conducted a study (study WA5) in which we assessed how much participants believe products work better for others while accounting for their personal usership of the products. We found evidence of the main effect in study WA5, though our research shows that at the product-level, users revealed mixed findings: we found a significant self-other difference (as predicted) for some products but not others. We are thus cautious about making conclusions based on self-usership. To determine the effect among users, we recommend a meta-analysis of product-level tests, which, by our account, using the data from study 1 (which provides the most conservative effect size given its treatment of products and participants), the meta-analysis would need to contain at least 33 effects (33 unique products) for an effect size, $d=0.13$, at an average number of participants per cell (target-judgment), $n=112$, with .80 power and .05 alpha, for low, moderate, and high heterogeneity of product-effects (cf. Valentine, Pigott, and Rothstein 2010). Needless to say, this could be fruitful future research (requiring at least 7,392 data-points; $33 \times 112 \times 2$ ). Other tests may also be possible, but given that the self-other effect among users varies according to which product is tested, researchers should examine its effect among multiple products. 
Indeed, besides product efficacy judgments, many documented effects in the consumer literature might be different if usership were taken into account. In relation to usership, a rich area of work on ownership has been conducted - the majority of it on products that study participants own for mere minutes. Thus, despite some similarity between ownership and usership, what happens among self-selecting users of a product is far from self-evident. A study of users might bring the literature new moderators and mechanisms not just for product efficacy, but for many other behaviors and judgments of interest to consumer researchers. As an example, Polman and Maglio (2017) found that gift-recipients like gifts more when giftgivers indicated they are users of the gifted products.

\section{CONCLUSION}

It cannot be the case that, writ large, products work better for others. Yet, our studies indicate that consumers reach this conclusion. We find this effect occurs because of two related social biases: consumers think others are less unique and more malleable than themselves. In all, our paper shows that an analysis of perceived product efficacy promises to be a worthwhile and interesting direction for future research. While products are thought to be part of consumers' self-concept (Belk 1988), consumers appear to believe this is more true of others' self-concept than of their own. 


\section{APPENDIX A: MEASUREMENT-ITEMS PER PRODUCT (STUDY 1)}

\begin{tabular}{|c|c|}
\hline Product & Measures $^{\mathrm{a}}$ \\
\hline Moisturizer & $\begin{array}{l}\text { Using a moisturizer will help to hydrate my skin. } \\
\text { My skin will be hydrated quickly after using a moisturizer. }\end{array}$ \\
\hline $\begin{array}{l}\text { Productivity/work- } \\
\text { management app }\end{array}$ & $\begin{array}{l}\text { Using a productivity/work-management app will help to improve my overall productivity. } \\
\text { My overall productivity will be improved quickly after using a productivity/work- } \\
\text { management app. }\end{array}$ \\
\hline Relaxation lamp & $\begin{array}{l}\text { Using a relaxation lamp will help to de-stress. } \\
\text { I will be de-stressed quickly after using a relaxation lamp. }\end{array}$ \\
\hline $\begin{array}{l}\text { White noise sound } \\
\text { machine }\end{array}$ & $\begin{array}{l}\text { Using a white noise sound machine will help me to concentrate. } \\
\text { I will concentrate quickly after using a white noise sound machine. }\end{array}$ \\
\hline Coloring book & $\begin{array}{l}\text { Using a coloring book will help to improve my creativity. } \\
\text { My creativity will be quickly improved after using a coloring book. }\end{array}$ \\
\hline $\begin{array}{l}\text { Percussion } \\
\text { massage gun }\end{array}$ & $\begin{array}{l}\text { Using a percussion massage gun will help to reduce my muscle tension. } \\
\text { My muscle tension will be quickly reduced after using a percussion massage gun. }\end{array}$ \\
\hline Energy lamp & $\begin{array}{l}\text { Using an energy lamp will to boost my energy levels while inside. } \\
\text { While inside, my energy levels will be quickly boosted after using energy lamp. }\end{array}$ \\
\hline $\begin{array}{l}\text { Deep sleep pillow } \\
\text { spray }\end{array}$ & $\begin{array}{l}\text { Using a deep sleep pillow spray will help to improve my sleep quality. } \\
\text { My sleep quality will be quickly improved after using a deep sleep pillow spray. }\end{array}$ \\
\hline Energy drink & $\begin{array}{l}\text { Drinking an energy drink will help me to stay awake. } \\
\text { I will be awake quickly after drinking an energy drink. }\end{array}$ \\
\hline Sunscreen & $\begin{array}{l}\text { Using sunscreen will help to protect my skin against sunburn. } \\
\text { My skin will be quickly protected against sunburn after using sunscreen. }\end{array}$ \\
\hline $\begin{array}{l}\text { Plant-based oil } \\
\text { extract }\end{array}$ & $\begin{array}{l}\text { Using a plant-based oil extract will help me to relax. } \\
\text { I will be quickly relaxed after using a plant-based oil extract. }\end{array}$ \\
\hline Bronzing cream & $\begin{array}{l}\text { Using a bronzing cream will help me to get a suntan. } \\
\text { I will quickly get a suntan after using a bronzing cream. }\end{array}$ \\
\hline Granola bar & $\begin{array}{l}\text { Eating a granola bar will help to satisfy my hunger. } \\
\text { My hunger will be quickly satisfied after eating a granola bar. }\end{array}$ \\
\hline E-cigarette & $\begin{array}{l}\text { Having an e-cigarette will damage my health. } \\
\text { My health will be quickly damaged after having an e-cigarette. }\end{array}$ \\
\hline $\begin{array}{l}\text { Aromatherapy } \\
\text { diffuser }\end{array}$ & $\begin{array}{l}\text { Using an aromatherapy diffuser will help to enhance my mood. } \\
\text { My mood will be quickly enhanced after using an aromatherapy diffuser. }\end{array}$ \\
\hline Elderberry & $\begin{array}{l}\text { Consuming elderberry will help to improve my immune system. } \\
\text { My immune system will be quickly improved after consuming elderberry. }\end{array}$ \\
\hline Sports drink & $\begin{array}{l}\text { Drinking a sports drink will help to boost my energy. } \\
\text { My energy will be boosted quickly after drinking a sports drink. }\end{array}$ \\
\hline $\begin{array}{l}\text { Online open courses } \\
\text { (e.g., MOOC) }\end{array}$ & $\begin{array}{l}\text { Taking online open courses (e.g., MOOC) will help me to learn something new. } \\
\text { I will quickly learn something new after taking online open courses (e.g., MOOC). }\end{array}$ \\
\hline $\begin{array}{l}\text { Language-learning } \\
\text { app (e.g., Duolingo) }\end{array}$ & $\begin{array}{l}\text { Using a language-learning app (e.g., Duolingo) will help my language acquisition. } \\
\text { My language acquisition will be quickly helped after using a language-learning app (e.g., } \\
\text { Duolingo). }\end{array}$ \\
\hline $\begin{array}{l}\text { Vocabulary-learning } \\
\text { app }\end{array}$ & $\begin{array}{l}\text { Using a vocabulary-learning app will help my vocabulary acquisition. } \\
\text { My vocabulary acquisition will be quickly helped after using a vocabulary-learning app. }\end{array}$ \\
\hline Self-help book & $\begin{array}{l}\text { Reading a self-help book will help my general improvement. } \\
\text { My general improvement will be quickly helped after reading a self-help book. }\end{array}$ \\
\hline $\begin{array}{l}\text { Tempurpedic } \\
\text { mattress }\end{array}$ & $\begin{array}{l}\text { Using a tempurpedic mattress will help to reduce my back pain. } \\
\text { My back pain will be quickly reduced after using a tempurpedic mattress. }\end{array}$ \\
\hline Steroids & $\begin{array}{l}\text { Using steroids will help to improve my athletic performance. } \\
\text { My athletic performance will be quickly improved after using steroids. }\end{array}$ \\
\hline Cooking lessons & $\begin{array}{l}\text { Taking cooking lessons will help to enhance my cooking skills. } \\
\text { My cooking skills will be quickly enhanced after taking cooking lessons. }\end{array}$ \\
\hline
\end{tabular}

a Measures reported here are the items in the "self" condition. The judgment-target is "other people" in the "other" condition. Participants responded to each item from 1 (strongly disagree) to 7 (strongly agree). 


\section{REFERENCES}

Alicke, Mark D. (1985), “Global Self-evaluation as Determined by the Desirability and Controllability of Trait Adjectives," Journal of Personality and Social Psychology, 49(6), 1621-30.

Apfelbaum, Evan P., Anne C. Krendl, and Nalini Ambady (2010), “Age-related Decline in Executive Function Predicts Better Advice-Giving in Uncomfortable Social Contexts," Journal of Experimental Social Psychology, 46(6), 1074-7.

Argo, Jennifer J., and Darren W. Dhal (2020), “Social Influence in the Retail Context: A Contemporary Review of the Literature," Journal of Retailing, 96(1), 25-39.

Barasz, Kate, Tami Kim, and Leslie K. John (2016), “The Role of (Dis) Similarity in (Mis) Predicting Others' Preferences," Journal of Marketing Research, 53(4), 597-607.

Barr, Dale J., Roger Levy, Christoph Scheepers, and Harry J. Tily (2013), “Random Effects Structure for Confirmatory Hypothesis Testing: Keep It Maximal,” Journal of Memory and Language, 68(3), 255-78.

Baskin, Ernest, Cheryl J. Wakslak, Yaacov Trope, and Nathan Novemsky (2014), "Why Feasibility Matters More to Gift Receivers than to Givers: A Construal-level Approach to Gift Giving," Journal of Consumer Research, 41(1), 169-82.

Bazerman, Max H., Francesca Gino, Lisa L. Shu, and Chia-Jung Tsay (2011), “Joint Evaluation as a Real-World Tool for Managing Emotional Assessments of Morality," Emotion Review, 3(3), 290-2.

Beggan, James K. (1992), “On the Social Nature of Nonsocial Perception: The Mere Ownership Effect,” Journal of Personality and Social Psychology, 62(2), 229-37.

Belk, Russell W. (1988), "Possessions and the Extended Self," Journal of Consumer Research, 15(2), 139-68. 
Berger, Jonah, and Chip Heath (2007), "Where Consumers Diverge from Others: Identity Signaling and Product Domains," Journal of Consumer Research, 34(2), 121-34.

Brasel, S. Adam, and James Gips (2011), “Red Bull ‘Gives You Wings’ for Better or Worse: A Double-Edged Impact of Brand Exposure on Consumer Performance," Journal of Consumer Psychology, 21(1), 57-64.

Brauer, Markus, and John J. Curtin (2018), "Linear Mixed-effects Models and the Analysis of Nonindependent Data: A Unified Framework to Analyze Categorical and Continuous Independent Variables that Vary Within-Subjects and/or Within-Items," Psychological Methods, 23(3), 389-411.

Brick, Danielle J., Lingrui Zhou, Tanya L. Chartrand, and Gavan J. Fitzsimons (2021), "Better to Decide Together: Shared Consumer Decision Making, Perceived Power, and Relationship Satisfaction," Journal of Consumer Psychology.

Chae, Boyoun, Xiuping Li, and Rui Zhu (2013), “Judging Product Effectiveness from Perceived Spatial Proximity," Journal of Consumer Research, 40(2), 317-35.

Cheek, Nathan N., and Eldar Shafir, "The Thick Skin Bias in Judgments about People in Poverty," Behavioural Public Policy, 1-26.

Cian Luca, Aradhna Krishna, and Chiara Longoni (2020), “Advertising a Desired Change: When Process Simulation Fosters (vs. Hinders) Credibility and Persuasion," Journal of Marketing Research, 57(3), 489-508.

Cryder, Cynthia E., George Loewenstein, and Richard Scheines (2013), "The Donor is in the Details," Organizational Behavior and Human Decision Processes, 120(1), 15-23.

Danziger, Shai, Ronit Montal, and Rachel Barkan (2012), "Idealistic Advice and Pragmatic Choice: A Psychological Distance Account,” Journal of Personality and Social Psychology, 102(6), 1105-17. 
Davison, W. Phillips (1983), "The Third-person Effect in Communication," Public Opinion Quarterly, 47 (1), 1-15.

Dawar, Niraj, and Philip Parker (1994), “Marketing Universals: Consumers’ Use of Brand Name, Price, Physical Appearance, and Retailer Reputation as Signals of Product Quality," Journal of Marketing, 58(2), 81-95.

Dhar, Ravi, and Klaus Wertenbroch (2000), "Consumer Choice Between Hedonic and Utilitarian Goods," Journal of Marketing Research, 37(1), 60-71.

Diekmann, Kristina A., Sheli D. Sillito Walker, Adam D. Galinsky, and Ann E. Tenbrunsel (2013), "Double Victimization in the Workplace: Why Observers Condemn Passive Victims of Sexual Harassment," Organization Science, 24(2), 614-28.

Dunning, David (2007), "Self-image Motives and Consumer Behavior: How Sacrosanct SelfBeliefs Sway Preferences in the Marketplace," Journal of Consumer Psychology, 17(4), 237-49.

Dunning, David, Chip Heath, and Jerry M. Suls (2004), "Flawed Self-assessment: Implications for Health, Education, and the Workplace," Psychological Science in the Public Interest, 5(3), 69-106.

Fishbach, Ayelet, Ying Zhang, and Yaacov Trope (2010), “Counteractive Evaluation: Asymmetric Shifts in the Implicit Value of Conflicting Motivations," Journal of Experimental Social Psychology, 46(1), 29-38.

Folkes, Valerie S., Ingrid M. Martin, and Kamal Gupta (1993), "When to Say When: Effects of Supply on Usage," Journal of Consumer Research, 20(3), 467-77.

Fontenelle, Gail A., Amanda P. Phillips, and David M. Lane (1985), “Generalizing Across Stimuli as Well as Subjects: A Neglected Aspect of External Validity," Journal of Applied Psychology, 70(1), 101-7. 
Frederick, Shane (2012), “Overestimating Others' Willingness to Pay," Journal of Consumer Research, 39(1), 1-21.

Fromkin, Howard L., and Charles R. Snyder (1980), “The Search for Uniqueness and Valuation of Scarcity," in Social Exchange: Advances in Theory and Research, ed. Kenneth J. Gergen et al., New York: Plenum, 57-75.

Funder, David C., and Daniel J. Ozer (2019), "Evaluating Effect Size in Psychological Research: Sense and Nonsense," Advances in Methods and Practices in Psychological Science 2(2), 156-68.

Garcia-Rada, Ximena, Lalin Anik, and Dan Ariely (2019), “Consuming Together (versus Separately) Makes the Heart Grow Fonder," Marketing Letters, 30(1), 27-43.

Garcia-Rada, Ximena, Mary Steffel, Elanor F. Williams, and Michael Norton (2021), "Consumers Value Effort over Ease When Caring for Close Others," Journal of Consumer Research.

Givi, Julian, and Jeff Galak (2020), "Selfish Prosocial Behavior: Gift-Giving to Feel Unique," Journal of the Association for Consumer Research, 5(1), 34-43.

Gneezy, Uri, Elizabeth A. Keenan, and Ayelet Gneezy (2014), “Avoiding Overhead Aversion in Charity," Science, 346(6209), 632-35.

Gorlin, Margarita, and Ravi Dhar (2012), “Bridging the Gap Between Joint and Individual Decisions: Deconstructing Preferences in Relationships," Journal of Consumer Psychology, 22(3), 320-3.

Hastie, Reid, and Nancy Pennington (2000), "Explanation-based Decision Making," in Cambridge Series on Judgment and Decision Making. Judgment and Decision Making: An Interdisciplinary Reader, eds. Terry Connolly, Hal. R. Arkes, and Kenneth. R. Hammond, Cambridge: Cambridge University Press, 212-228. 
Hayes, Andrew F. (2013), Introduction to Mediation, Moderation, and Conditional Process Analysis, New York: Guilford Press.

Hoffman, Kelly M., Sophie Trawalter, Jordan R. Axt, and M. Norman Oliver, "Racial Bias in Pain Assessment and Treatment Recommendations, and False Beliefs About Biological Differences Between Blacks and Whites," Proceedings of the National Academy of Sciences, 113(16), 4296-301.

Ilyuk, Veronika, and Lauren Block (2016), "The Effects of Single-serve Packaging on Consumption Closure and Judgments of Product Efficacy," Journal of Consumer Research, 42(6), 858-78.

Irmak, Caglar, Lauren G. Block, and Gavan J. Fitzsimons (2005), “The Placebo Effect in Marketing: Sometimes You Just Have to Want It to Work," Journal of Marketing Research, 42(4), 406-9.

Judd, Charles M., Jacob Westfall, and David A. Kenny (2012), “Treating Stimuli as a Random Factor in Social Psychology: A New and Comprehensive Solution to a Pervasive but Largely Ignored Problem," Journal of Personality and Social Psychology, 103(1), 54-69.

(2017), "Experiments with More than One Random Factor: Designs, Analytic Models, and Statistical power," Annual Review of Psychology, 68, 601-25.

Jung, Minah H., Alice Moon, and Leif D. Nelson (2020), “Overestimating the Valuations and Preferences of Others," Journal of Experimental Psychology: General, 149(6), 11931214.

Klein, William M. (1997), “Objective Standards Are Not Enough: Affective, Self-evaluative, and Behavioral Responses to Social Comparison Information.” Journal of Personality and Social Psychology, 72(4), 763-74. 
Kunda, Ziva (1990), “The Case for Motivated Reasoning," Psychological Bulletin, 108(3), 480-98.

Kupor, Daniella, and Kristin Laurin (2020), "Probable Cause: The Influence of Prior Probabilities on Forecasts and Perceptions of Magnitude," Journal of Consumer Research, 46(5), 833-52.

Kurt Didem, Inman J. Jeffrey (2013), “Mispredicting Others’ Valuations: Self-Other Difference in the Context of Endowment," Journal of Consumer Research, 40 1, 78-89. Lin, Ying-Ching, and Chiu-chi Angela Chang (2012), "Double Standard: The Role of Environmental Consciousness in Green Product Usage," Journal of Marketing, 76(5) 125-34.

Linville, Patricia W. (1985), “Self-Complexity and Affective Extremity: Don’t Put All of Your Eggs in One Cognitive Basket," Social Cognition, 3(1), 94-120.

Liu, Peggy J., Steven K. Dallas, and Gavan J. Fitzsimons (2019), “A Framework for Understanding Consumer Choices for Others," Journal of Consumer Research, 46(3), 407-34.

Liu, Yi, Evan Polman, Yongfang Liu, and Jiangli Jiao (2018), "Choosing for Others and its Relation to Information Search," Organizational Behavior and Human Decision Processes, 147, 65-75.

Lu, Jingyi, Zhengyan Liu, and Zhe Fang (2016), “Hedonic Products for You, Utilitarian Products for Me," Judgment and Decision Making, 11(4), 332-41.

MacVean, Mary (2014), "For Many People, Gathering Possessions is Just the Stuff of Life," Los Angeles Times, 21.

Malle, Bertram F. (1999), “How People Explain Behavior: A New Theoretical Framework,” Personality and Social Psychology Review, 3(1), 23-48. 
Mata, André, Cláudia Simão, and Rogério Gouveia (2020), "Science Can Explain Other People's Minds, But Not Mine: Self-Other Differences in Beliefs About Science," Self and Identity.

Maglio, Sam J., Odelia Wong, Cristina D. Rabaglia, Evan Polman, Taly Reich, Julie Y. Huang, Hal E. Hershfield, and Sean P. Lane (2020), "Perceptions of Collaborations: How Many Cooks Seem to Spoil the Broth?” Social Psychological and Personality Science, 11(2), 236-43.

Montoya, Amanda K., and Andrew F. Hayes (2017), “Two-condition Within-Participant Statistical Mediation Analysis: A Path-Analytic Framework," Psychological Methods, 22(1), 6-27.

Olson, Jerry C., and Philip A. Dover (1979), "Disconfirmation of Consumer Expectations Through Product Trial," Journal of Applied Psychology, 64(2), 179-89.

Ordóñez, Lisa D., Barbara A. Mellers, Shi-Jie Chang, and Jordan Roberts (1995), “Are Preference Reversals Reduced When Made Explicit?” Journal of Behavioral Decision Making, 8(4), 265-77.

Pedregon, Cynthia A., Roberta L. Farley, Allison Davis, James M. Wood, and Russell D. Clark (2012), "Social Desirability, Personality Questionnaires, and the 'Better than Average' Effect," Personality and Individual Differences, 52(2), 213-7.

Polman, Evan (2010), “Information Distortion in Self-Other Decision Making,” Journal of Experimental Social Psychology, 46(2), 432-5.

Polman, Evan, and Kaiyang Wu (2020), “Decision Making for Others Involving Risk: A Review and Meta-analysis,” Journal of Economic Psychology, 77, 102184.

Polman, Evan, and Kyle J. Emich (2011), “Decisions for Others are More Creative than Decisions for the Self," Personality and Social Psychology Bulletin, 37(4), 492-501. 
Polman, Evan, and Rachel L. Ruttan (2012), "Effects of Anger, Guilt, and Envy on Moral Hypocrisy," Personality and Social Psychology Bulletin, 38(1), 129-39.

Polman, Evan, and Sam J. Maglio (2017), "Mere Gifting: Liking a Gift More Because It Is Shared," Personality and Social Psychology Bulletin, 43(11), 1582-94.

Polman, Evan, Daniel A. Effron, and Meredith R. Thomas (2018), “Other People's Money: Money's Perceived Purchasing Power Is Smaller for Others than for the Self," Journal of Consumer Research, 45(1), 109-25.

Pronin, Emily, Thomas Gilovich, and Lee Ross (2004), "Objectivity in the Eye of the Beholder: Divergent Perceptions of Bias in Self Versus Others," Psychological Review, 111(3), 781-99.

Quoidbach, Jordi, Daniel T. Gilbert, and Timothy D. Wilson (2013), "The End of History Illusion," Science, 339 (6115), 96-8.

Ratner, Rebecca K., and Barbara E. Kahn (2002), “The Impact of Private Versus Public Consumption on Variety-seeking Behavior," Journal of Consumer Research, 29(2), 246-57.

Reich, Taly, Daniella M. Kupor, and Rosanna K. Smith (2018), "Made by Mistake: When Mistakes Increase Product Preference," Journal of Consumer Research, 44(5), 10851103.

Rim, SoYon, Kate E. Min, Peggy J. Liu, Tanya L. Chartrand, and Yaacov Trope (2019), “The Gift of Psychological Closeness: How Feasible Versus Desirable Gifts Reduce Psychological Distance to the Giver," Personality and Social Psychology Bulletin, $45(3), 360-71$.

Ross, Lee, Mark R. Lepper, and Michael Hubbard (1975), "Perseverance in Self-Perception and Social Perception: Biased Attributional Processes in the Debriefing Paradigm," Journal of Personality and Social Psychology, 32(5), 880-92. 
Ruvio, Ayalla, Aviv Shoham, and Maja Makovec Brenčič (2008), “Consumers’ Need for Uniqueness: Short-form Scale Development and Cross-Cultural Validation," International Marketing Review, 25(1), 33-53.

Sande, Gerald N., George R. Goethals, and Christine E. Radloff (1988), “Perceiving One’s Own Traits and Others': The Multifaceted Self," Journal of Personality and Social Psychology, 54(1), 13-20.

Sharma, Eesha and Vicki G. Morwitz (2016), "Saving the Masses: The Impact of Perceived Efficacy on Charitable Giving to Single vs. Multiple Beneficiaries,” Organizational Behavior and Human Decision Processes, 135, 45-54.

Simonson, Itamar, and Stephen M. Nowlis (2000), “The Role of Explanations and Need for Uniqueness in Consumer Decision Making: Unconventional Choices Based on Reasons," Journal of Consumer Research, 27(1), 49-68.

Smith, Robert W., David Faro, and Katherine A. Burson (2013), "More for the Many: The Influence of Entitativity on Charitable Giving," Journal of Consumer Research, 39(5), 961-76.

Snyder, Charles R. (1992), "Product Scarcity by Need for Uniqueness Interaction: A Consumer Catch-22 Carousel?" Basic and Applied Social Psychology, 13(1), 9-24. Spencer, Steven J., Mark P. Zanna, and Geoffrey T. Fong (2005), “Establishing a Causal Chain: Why Experiments Are Often More Effective than Mediational Analyses in Examining Psychological Processes," Journal of Personality and Social Psychology, $89(6), 845-51$.

Summers, Kevin M., Jason C. Deska, Steven M. Almaraz, Kurt Hugenberg, and E. Paige Lloyd (2021), "Poverty and Pain: Low-SES People are Believed to be Insensitive to Pain,” Journal of Experimental Social Psychology, 95, 104116. 
Tamir, Diana I., and Jason P. Mitchell (2013), “Anchoring and Adjustment During Social Inferences," Journal of Experimental Psychology: General, 142(1), 151-162.

Valentine, Jeffrey C., Therese D. Pigott, and Hannah R. Rothstein (2010), “How Many Studies Do You Need? A Primer on Statistical Power for Meta-Analysis,” Journal of Educational and Behavioral Statistics, 35(2), 215-47.

Van Bergen, Noah, Caglar Irmak, and Julio Sevilla (2020), "Product Entitativity: How the Presence of Product Replicates Increases Perceived and Actual Product Efficacy," Journal of Consumer Research, 47(2), 192-214.

Waytz, Adam, Juliana Schroeder, and Nicholas Epley (2014), “The Lesser Minds Problem,” in Humanness and Dehumanization, eds. Jacques Philippe Leyens, Jeroen Vaes, and Paul G. Bain, United Kingdom: Taylor \& Francis, 49-67.

Weinstein, Neil D. (1980), “Unrealistic Optimism About Future Life Events,” Journal of Personality and Social Psychology, 39(5), 806-820.

Wells, Gary L., and Paul D. Windschitl (1999), "Stimulus Sampling and Social Psychological Experimentation," Personality and Social Psychology Bulletin, 25(9), 1115-25.

Westfall, Jacob, David A. Kenny, and Charles M. Judd (2014), "Statistical Power and Optimal Design in Experiments in which Samples of Participants Respond to Samples of Stimuli," Journal of Experimental Psychology: General, 143(5), 2020-45.

Wicklund, Robert A., and Peter M. Gollwitzer (1982), "Symbolic Self-Completion,” Hillsdale, NJ: Erlbaum.

Williams, Elanor F., and Mary Steffel (2014), "Double Standards in the Use of Enhancing Products by Self and Others," Journal of Consumer Research, 41(2), 506-25.

Williams, Elanor F., and Thomas Gilovich (2008), "Conceptions of the Self and Others across Time," Personality and Social Psychology Bulletin, 34(8), 1037-46. 
Wu, Eugenia C., Sarah G. Moore, and Gavan J. Fitzsimons (2019), "Wine for the Table: SelfConstrual, Group Size, and Choice for Self and Others," Journal of Consumer Research, 46(3), 508-27.

Yang, Adelle X., and Oleg Urminsky (2018), “The Smile-seeking Hypothesis: How Immediate Affective Reactions Motivate and Reward Gift Giving," Psychological Science, 29(8), 1221-33.

Zhao, Xinshu, John G. Lynch Jr, and Qimei Chen (2010), "Reconsidering Baron and Kenny: Myths and truths about Mediation Analysis," Journal of Consumer Research, 37(2), 197-206.

Zhu, Meng, Darron M. Billeter, and J. Jeffrey Inman (2012), “The Double-Edged Sword of Signaling Effectiveness: When Salient Cues Curb Postpurchase Consumption,” Journal of Marketing Research, 49(1), 26-38. 


\section{WEB APPENDIX}

\section{STUDY WA1}

Study WA1 (pre-registered, http://aspredicted.org/blind.php? $\mathrm{x}=63 \mathrm{mi} 3 \mathrm{k}$ ) aims to examine hypotheses 2 and 3 simultaneously. Here, we examined both mechanisms (perceived uniqueness and perceived malleability) that were previously found to affect perceived product efficacy via their separately manipulated effects, in studies 4A-4B and 5A-5B. In extension, in study WA1 we tested the mediators in tandem, in a parallel process-by-mediation design and analysis.

Method

We recruited 400 participants and received 383 participants on MTurk (180 females, $\left.M_{\text {age }}=40.26, S D_{\text {age }}=11.77\right)$. We randomly assigned participants into two conditions (judgment-target: self vs. other), and asked participants to assess four products' efficacy, in random order: coffee for staying awake, lavender oil extract for relaxing, sleeping pills for sleeping, and natural mosquito spray for keeping mosquitos away. In the self-condition, we asked participants how efficacious the products would be for themselves. In the othercondition, we asked participants how efficacious the products would be for "MTurk Worker \#131, who participated in a similar survey earlier this year." Participants responded with each product's perceived efficacy on a scale from 1 (not at all) to 7 (very much). Then, we asked participants to estimate their judgment-target's perceived uniqueness and malleability (e.g., in the self-condition, "how unique are you?" and "how resistant to changes do you think your 
body is?"), both answered from 1 (not at all) to 7 (very much); the latter item was reversescored.

As a robustness check, we conducted a confirmatory factor analysis on the two mediating and dependent variables. Zhao, Lynch, and Chen (2010) suggested this approach to assess if mediators are sufficiently distinct from outcome measures in a causal chain. If one factor fits the data, then the variables risk measuring the same construct; however, if three factors fit the data, then the three measures are distinct. In support of the constructs' differentiation, a three-factor model fit the data very well, CFI $=.954$, RMSEA $=.058$, and fit significantly better than a one-factor model, $\chi^{2}(1)=7.10, p=.008$.

Results

We averaged participants' efficacy judgments to the four products to create the dependent measure, perceived product efficacy $(\alpha=0.61)$. As in the other studies, we found that participants believed that products would be more efficacious for others $(M=4.86, S D=$ $0.96)$ than for themselves $(M=4.57, S D=1.07), t(381)=2.83, p=.005, d=0.29$. In separate tests, we also found that participants perceived themselves to be more unique $(M=4.83, S D=$ 1.56) than others $(M=4.42, S D=1.46), t(381)=2.66, p=.008, d=0.27$; and less malleable $(M=3.70, S D=1.38)$ than others $(M=3.97, S D=1.28), t(381)=1.99, p=.047, d=0.20$.

Because participants perceived that products would be more efficacious for others, and also perceived others to be less unique and more malleable, we sought to examine whether the two latter perceptions might, in parallel, account for the former perception. We constructed a parallel mediation model (Model 4; Hayes 2013), and tested whether perceived uniqueness and perceived malleability account for the relationship between judgment-target and perceived product efficacy. Using a bootstrapping procedure, one thousand repeated random 
samples were taken from the data to compute this indirect effect. We found that the relation between judgment-target and perceived product efficacy was mediated, in parallel, by perceived uniqueness, $b=0.08, S E=0.04,95 \% \mathrm{CI}=[0.02,0.17]$, and perceived malleability, $b=0.03, S E=0.02,95 \% \mathrm{CI}=[0.01,0.07]$. The direct effect remained significant, $b=0.41$, $S E=0.10,95 \% \mathrm{CI}=[0.22,0.60]$

\section{Discussion}

This study extended our findings to a wider range of products, and shows once more that people believe products are more efficacious for others than they are for themselves. Of import, we confirm why people possess this asymmetric perception. People think others are less unique and more malleable than they are themselves. We find that product efficacy perceptions are related to both of these self-other judgments. Although it might be desirable to believe that the self is more unique than others and less malleable, these judgments in turn lead people to the conclusion that products will work less well for themselves. Moreover, it does not appear in our data that one of these judgments is more influential than the other. The indirect effects of perceived uniqueness and malleability are not statistically distinguishable, suggesting that both have a relatively equal mediating effect of judgment-target on perceived product efficacy. That is, the results to the analysis show that each mediator has its own effect on perceived product efficacy. In support, we conducted mediation tests with each mediator analyzed separately in the chain, and in both cases the indirect effect emerged significant, for perceived uniqueness, $b=0.09, S E=0.04,95 \% \mathrm{CI}=[0.02,0.18]$; for perceived malleability, $b=0.05, S E=0.03,95 \% \mathrm{CI}=[0.01,0.11]$.

\section{STUDY WA2}


In study WA2, we tested whether products' baseline efficacy alters the size of the selfother difference in perceived product efficacy. We investigated this in two different ways. First, we carried out an experiment in which we manipulated products' efficacy, and measured participants' efficacy judgments with a comparative dependent measure-which has the benefit of mitigating ceiling effects. It follows that at a high level of baseline efficacy, the self-other difference would be smaller because at higher levels, there is less area on a Likert scale to render the hypothesized self-other difference. In this study then, we asked participants to respond with how much, in relative terms, a product works better for others (or for themselves). Second, we conducted a quartile-analysis of the products we tested throughout our studies. Specifically, we tabulated the products by ranking them according to participants' self-ratings of efficacy. We then calculated the average self-other difference in each quartile. This test allows us to identify the effect size at different levels of baseline efficacy.

Method

First, we recruited 149 participants on MTurk to carry out a pre-test (1 participant failed an attention check at the end of the survey, by replying "yes" to the question "have you ever been on the planet Mars?"). This left 148 valid participants ( 81 males, 64 females, $M_{\text {age }}=$ $\left.38.28, S D_{\text {age }}=10.63\right)$. We presented these participants with versions of products that varied in their efficacy level, from regular to strong to very strong (viz. regular energy drink, strong energy drink, very strong energy drink, regular painkiller, strong painkiller, very strong pain killer). We asked participants to rate the products' effectiveness from 1 (not at all) to 7 (very 
much). This test furnished a baseline level of efficacy for each product and its respective version.

After this pre-test, we recruited 273 participants from MTurk (7 participants failed the same attention check as in the pre-test). This left 266 valid participants (128 males, 134 females, $M_{\text {age }}=39.02, S D_{\text {age }}=12.32$ ). We asked these participants to rate the pre-tested products according to how effective they are for themselves relative to others, from 1 (most effective for myself), 4 (equally effective for myself as for another person in this survey), to 7 (most effective for another person in this survey). The midpoint on this scale indicates that products are judged to be as effective for others as they are for themselves. In this vein, this measure can account for products with high efficacy without "hitting the scale ceiling" because all products, regardless of their baseline efficacy, have equal potential to render the same difference in self- and social-judgments.

Finally, we conducted a separate analysis that contained the products that we tested throughout our studies. Specifically, we ranked the products by participants' self-rating of efficacy, and then calculated the average self-other difference in each quartile, thereby furnishing an effect size among products with low product efficacy (bottom quartile), low-tomedian product efficacy (second quartile), median-to-high product efficacy (third quartile), and high product efficacy (top quartile).

Results

The baseline per-product efficacy ratings to the pre-test are reported in table WA1, along with the self-ratings of product efficacy from products tested in our other studies, totaling 49 products. Of import, the baseline efficacy rating significantly varied among the three levels of efficacy: regular, strong, and very strong, $F(2,294)=105.00, p<.001$, 
whereby the very strong versions of the products were perceived to be more efficacious $(M=$ $5.61, S D=1.01)$ than the strong versions $(M=4.91, S D=0.97), p_{\text {Tukey }}<.001$, which in turn were perceived to be more efficacious than the regular versions $(M=4.27, S D=1.10), p_{\text {Tukey }}$ $<.001$. Next, we tested the self-other differences among the products; these results are also in table WA1. For summary, all three efficacy-levels rendered a significant self-other difference. Of note, the very strong versions evidenced the largest self-other difference $\left(M_{\text {difference }}=0.70\right.$, $t(265)=8.08, p<.001, d=0.50)$, which was significantly larger than both the strong $\left(M_{\text {difference }}=0.48, t(265)=7.07, p<.001, d=0.43\right), p_{\text {Tukey }}=.012$, and regular versions' differences $\left(M_{\text {difference }}=0.44, t(265)=6.21, p<.001, d=0.38\right), p_{\text {Tukey }}=.003$ (the strong and regular versions' differences were not significantly different, $\left.p_{\text {Tukey }}=.885\right)$. Together, this shows the effect is robust to product efficacy level.

In more support, we conducted the quartile-analysis, which shows the average selfother difference among the 49 products that we tested throughout our studies. We ranked the products according to participants' self-rating of efficacy (in ascending order), and then calculated the average effect size for the self-other difference per quartile (see table WA1). The effect sizes were $d \mathbf{s}=0.35,0.27,0.18$, and 0.11 , from the first to fourth quartile respectively. To be sure, the effect sizes decrease as baseline efficacy-ratings increase. This is illustrative of a ceiling effect: as the baseline efficacy-rating increases on a Likert scale (e.g., from 4.00 to 6.75 , on a 1-7 scale), the possible maximal self-other difference logically decreases (from 3.00 to 0.25 ). It is noteworthy that among products that are median-to-highefficacy (products in the third quartile), the effect size, $d=0.18$, is typical of effects in psychology (Funder and Ozer 2019); for context, a $d=0.18$ effect size is larger than the effect of taking ibuprofen for pain relief. In sum, the self-other effect evidences among all kinds of products that range in efficacy from low to high. 
Table WA1. Self-Other Difference in Efficacy by Baseline Efficacy (study WA2)

\begin{tabular}{|c|c|c|c|}
\hline $\begin{array}{c}\text { Baseline } \\
\text { Efficacy Rating }\end{array}$ & $\begin{array}{l}\text { Self-Other } \\
\text { Difference } \\
\text { (Cohen's } d \text { ) }\end{array}$ & Product & Study \\
\hline \multicolumn{4}{|l|}{ First Quartile } \\
\hline 2.64 & 0.41 & one cup of water & 7 \\
\hline 2.97 & 0.14 & anti-aging cream & WA5 \\
\hline 3.19 & 0.74 & device to improve mood & $3 A$ \\
\hline 3.40 & 0.15 & relaxation lamp & WA5 \\
\hline 3.47 & 0.68 & vaccine & WA4 \\
\hline 3.52 & 0.39 & regular drink & WA2 \\
\hline 3.63 & 0.40 & energy lamp & 1 \\
\hline 3.67 & 0.04 & aromatherapy diffuser & WA5 \\
\hline 3.68 & 0.42 & coloring book & 1 \\
\hline 3.76 & 0.42 & reading aid & 6 \\
\hline 3.92 & 0.21 & lavender oil & WA5 \\
\hline 3.93 & 0.21 & deep sleep pillow spray & 1 \\
\hline Average Effect & 0.35 & & \\
\hline \multicolumn{4}{|l|}{ Second Quartle } \\
\hline 3.95 & 0.33 & relaxation lamp & 1 \\
\hline 3.97 & 0.13 & productivity/work-management app & WA5 \\
\hline 4.10 & 0.54 & white-noise machine & 1 \\
\hline 4.17 & 0.28 & white-noise machine & WA5 \\
\hline 4.19 & 0.22 & elderberry syrup & 1 \\
\hline 4.20 & 0.27 & aromatherapy diffuser & 1 \\
\hline 4.22 & 0.26 & five cups of water & 7 \\
\hline 4.36 & 0.11 & plant-based oil extract & 1 \\
\hline 4.40 & 0.10 & self-help book & 1 \\
\hline 4.41 & 0.67 & social distancing & WA3 \\
\hline 4.47 & 0.21 & bronzing cream & $4 \mathrm{~B}$ \\
\hline 4.56 & 0.14 & mosquito spray & WA1 \\
\hline Average Effect & 0.27 & & \\
\hline \multicolumn{4}{|l|}{ Third Quartle } \\
\hline 4.62 & 0.35 & strong drink & WA2 \\
\hline 4.65 & 0.17 & productivity app & 1 \\
\hline 4.67 & 0.07 & online courses & 1 \\
\hline 4.70 & 0.20 & bronzing cream & 1 \\
\hline 4.72 & 0.16 & coffee & WA1 \\
\hline 4.80 & 0.15 & sports drink & 1 \\
\hline 4.80 & 0.30 & device to improve mood & $3 B$ \\
\hline 4.81 & 0.22 & tempurpedic mattress & 1 \\
\hline 4.86 & 0.35 & steroids & 1 \\
\hline 4.92 & -0.06 & language-learning app & 1 \\
\hline 5.03 & 0.18 & regular painkiller & WA2 \\
\hline 5.06 & 0.05 & vocabulary-learning app & 1 \\
\hline Average Effect & 0.18 & & \\
\hline \multicolumn{4}{|l|}{ Fourth Quartle } \\
\hline 5.07 & -0.01 & teeth whitening strips & 1 \\
\hline 5.08 & 0.08 & granola bar & 1 \\
\hline 5.09 & 0.27 & sleeping pills & WA1 \\
\hline 5.20 & 0.29 & strong painkiller & WA2 \\
\hline 5.21 & 0.34 & very strong drink & WA2 \\
\hline 5.29 & 0.04 & energy drink & 1 \\
\hline 5.36 & 0.17 & e-cigarette & 1 \\
\hline 5.43 & -0.16 & percussion massage gun & 1 \\
\hline 5.62 & -0.24 & cooking lessons & 1 \\
\hline 5.89 & -0.18 & moisturizer & 1 \\
\hline 5.90 & 0.33 & coloring book & $5 \mathrm{~B}$ \\
\hline 6.01 & -0.06 & sunscreen & 1 \\
\hline 6.02 & 0.50 & very strong painkiller & WA2 \\
\hline Average Effect & 0.11 & & \\
\hline
\end{tabular}

Note: Products from all studies were included except for study 2, because this study used a comparative dependent measure, which does not allow for a baseline efficacy rating. Products from studies WA3 and WA4 were measured on 5-item scales; statistics in table from these studies were converted to 7-item scale statistics. Baseline efficacy level for products from study WA2 were based on the pre-test results. 


\section{STUDY WA3}

We recruited 200 participants from MTurk and received 210 participants. We randomized participants into two judgment-target conditions (self vs. other), asking participants about the perceived efficacy of social distancing (we conducted this study in March 2020). In the self-condition, we asked participants how much they think social distancing will help them ("How much do you think your social distancing will affect your health?"). In the other-condition, we asked participants how much they think others' social distancing will help other people ("How much do you think others' social distancing will affect their health?”). Participants responded to their respective question on a scale from 1 (not at all) to 5 (a great deal).

Results

We found that participants believed that social distancing would be more efficacious for others $(M=3.90, S D=0.92)$ than for themselves $(M=3.15, S D=1.30), t(208)=4.85, p<$ $.001, d=0.67$

\section{STUDY WA4}

We recruited 200 participants from MTurk and received 216 participants. We randomized participants into two judgment-target conditions (self vs. other), asking participants about the perceived efficacy of the COVID-19 vaccine (we conducted this study in March 2021). In the self-condition, we asked participants how much they think the vaccine will help them ("How much do you think taking the COVID-19 vaccine will affect your 
health?"). In the other-condition, we asked participants how much they think the vaccine will help other people ("How much do you think the COVID-19 vaccine will affect other people's health when other people get the vaccine?"). Participants responded to their respective question on a scale from 1 (not at all) to 5 (a great deal).

Results

We found that participants believed that the vaccine would be more efficacious for others $(M=3.30, S D=1.27)$ than for themselves $(M=2.48, S D=1.14), t(214)=4.95, p<$ $.001, d=0.68$

\section{STUDY WA5}

Study WA5 (pre-registered, http://aspredicted.org/blind.php? $\mathrm{x}=\mathrm{i} 6 \mathrm{fy} 9 \mathrm{t}$ ) expands on the other studies by examining participants' self-selected usership. Specifically, we measured whether participants are users of the products for which we ask their perceived product efficacy judgments. When participants are self-selecting users (or buyers) of a product, then they may be more likely to assess its product efficacy to be relatively high. Consumers are not likely buying nor using products if they do not believe that they work, therefore it stands to reason that among users, the self-other difference could attenuate.

Method

We recruited 500 participants from MTurk and received 536 participants (251 females, $\left.M_{\mathrm{age}}=36.52, S D_{\mathrm{age}}=11.04\right)$. We randomized participants into two judgment-target conditions 
(self vs. other), asking participants about the perceived efficacy of five products: anti-aging cream, a productivity/work-management app, an aromatherapy diffuser, a white-noise machine, and a relaxation lamp. In the self-condition, we asked participants how much they think each product will help them ("How much do you think using [product name] will help you to obtain the claimed benefit?"). In the other-condition, we asked participants how much they think each product will help the average person ("How much do you think using [product name] will help the average person to obtain the claimed benefit?"). Participants responded to each product's efficacy item on a scale from 1 (not at all) to 7 (a lot). We also asked participants to answer a yes-or-no question (per product) to whether they use the product.

Results

We averaged participants' responses to the five product ratings to create the dependent measure, perceived product efficacy ( $\alpha=.73$ ). Supporting our hypothesis, participants believed that products would be more efficacious for others $(M=3.88, S D=1.01)$ than for themselves $(M=3.64, S D=1.29), t(534)=2.43, p=0.015, d=0.21$.

Next, we examined this basic effect among users. We examined each product individually, and compared both non-users' efficacy judgments and users' judgments (see table WA2). We found that out of the five products judged by non-users, four of the self-other differences were significant, and one was marginal. The differences appear to be less strong among users. Out of the five products, two of the self-other differences were significant in the opposite direction, and three were not significant.

\section{Discussion}


Study WA5 shows more evidence that people believe that products will be more efficacious for others than for themselves. In addition to finding more evidence for the effect, we also tested a potential boundary condition, self-usership, and whether among non-users and users, the self-other difference in perceived product efficacy is different. It follows that compared to non-user participants, participants may believe that products they willingly use are more efficacious. That is, users consume picked products precisely because they have confidence in those products delivering benefits (put differently, non-users may have especially low levels of confidence or interest in products' efficacy, which could explain why they neither pick nor use certain products).

Although there appears to be a clear divergence in the effect among non-users, the effect is not clear among users. It appears thus: the effect is reliable among non-users, yet when usership is accounted for, the effect is mixed — which is to say that we find significant self-other differences among users in studies 5B and 7 (in the predicted direction) — though we find small, non-significant differences in study WA5.

Table WA2. Descriptive Statistics and Results of Usership per Product (study WA5)

\begin{tabular}{|c|c|c|c|}
\hline \multirow{2}{*}{ Product } & \multicolumn{2}{|c|}{ Perceived Product Efficacy } & \multirow{2}{*}{$p$ value $^{a}$} \\
\hline & Self $(S D)$ & Other $(S D)$ & \\
\hline \multicolumn{4}{|l|}{ Non-User } \\
\hline Anti-aging cream & $2.37(1.37)$ & $2.89(1.42)$ & $<0.01$ \\
\hline Productivity/work-management app & $3.48(1.60)$ & 3.95 (1.39) & $<0.01$ \\
\hline Aromatherapy diffuser & $3.20(1.73)$ & $3.46(1.52)$ & 0.09 \\
\hline White-noise machine & $3.61(1.87)$ & $4.43(1.38)$ & $<0.01$ \\
\hline Relaxation lamp & $3.23(1.79)$ & $3.56(1.40)$ & 0.03 \\
\hline \multicolumn{4}{|l|}{ User } \\
\hline Anti-aging cream & $4.71(1.51)$ & $4.41(1.25)$ & 0.23 \\
\hline Productivity/work-management app & $5.41(1.25)$ & $5.00(1.16)$ & 0.11 \\
\hline Aromatherapy diffuser & $5.36(1.41)$ & $4.76(1.47)$ & 0.03 \\
\hline White-noise machine & $5.92(1.51)$ & $5.36(1.47)$ & 0.03 \\
\hline Relaxation lamp & $5.08(1.75)$ & $4.57(1.47)$ & 0.30 \\
\hline
\end{tabular}

${ }^{a} p$-values represent results of $t$-tests between self- and other-conditions. 